\title{
Fabricating a Low-cost and Low-immune Xenogeneic Aortic Valve Bio Prosthesis
}

\section{Sonal Walawalkar}

HEALTH BIOLABS, Division of Tissue Engineering \& Cell Science (TECS), Shree Hospital \& Research Institute (SHRI), 1st Lane Rajarampuri, Bus Route, Kolhapur-416008, Maharashtra State, India

Shahdab Almelkar ( $\sim$ healthbiolabs@gmail.com )

HEALTH BIOLABS (HBL), https://orcid.org/0000-0001-5330-0726

Savvas Christoforidis

Biomedical Research Division, Institute of Molecular Biology and Biotechnology, Foundation for Research and Technology, Department of Medicine, University of Ioannina, Greece. 3 Laboratory of Biological Chemistry, Faculty of Health Sciences, University of loannina, Greece

Subha N Rath

Regenerative Medicine \& Stem Cell Lab, Department of Biomedical Engineering, Indian Institute of Technology Hyderabad (IITH), Kandi campus, Telangana State, India

Research

Keywords: Aortic Valve, Heart Perfusion, decellularization, tensile testing, ECM, vWF, Lectin

Posted Date: November 10th, 2021

DOI: https://doi.org/10.21203/rs.3.rs-1023576/v1

License: (c) (1) This work is licensed under a Creative Commons Attribution 4.0 International License. Read Full License 


\section{Abstract}

Background

Cardiac valve replacement is the only available treatment for end-stage valvular dysfunction patients. In this treatment, among the available choices of valves, the bio-prosthetic valves are better than the mechanical ones in terms of hemodynamic and infection-resistant properties. However, they tend to fail with time, posing a catastrophic event. This study focuses on fabricating the heart valve to eliminate the flaws of bio-prosthetic valves.

Methods

Perfusion-based decellularization method was adapted for decellularisation to the sheep heart. Further, decellularised aortic valves were cross-linked with $0.2 \%$ Glutaraldehyde (Group C).

Results

All valves were tested for biochemical and molecular assays including biomechanical tensile testing. Histology, SEM showed a complete lack of cells with intact matrix for decellularised groups. The fibrin glue coated valves leaflet scaffolds showed remodeling of the cells as per the matrix (plasticity). Characterization studies emphasized the cellular behaviour onto matrigel assay, live-dead assay, and the expression of vWF, glycocalyx lectin.

\section{Conclusions}

This study focuses on fabricating a re-endothelialized xenogeneic aortic valve leaflet using cross-linking reaction to mask antigenicity of the host proteins (low-immune humanized) and avoid post-implantation cross-reaction.

\section{Introduction}

Heart valve complications are commonly encountered in congenital heart diseases, rheumatic heart diseases (RHD), and myocardial infarction (MI). There are no advanced biotherapeutic and pharmaceutical drugs available to treat valvular heart diseases [1]. Some of the most common heart valvular diseases are aortic and mitral valve stenosis, calcification of the valve leaflets due to aging [2], inflammation, and thrombosis of leaflets due to reactive oxygen species (ROS) [3]. The treatments available for valve stenosis and dysfunction are balloon valvuloplasty [4], failure of which leaves us with the sole option to replace the valve surgically. The usual preference for young patients is mechanical valves, whereas, for older age groups, the bioprosthetic valves are favored. However, there is a debate about the optimal valves for the age group between 50 and 70 years [5]. Bioprosthetic valves are preferred over mechanical valves due to complications that accompany the later ones, such as hemolysis. However, with time, the main complexity of bioprosthetic valves is a sudden failure with catastrophes [5].

Bioprosthetic valves are usually prepared by decellularizing (SDS, Triton-X) or using cross-linking agents such as glutaraldehyde, etc. An aspect of the crosslinked valve is graft and host-tissue-specific integrity. It masks antigenic sites by the aldehyde-based polymer. The cross-linked polymer-based aldehyde solutions are excellent in sterilizing the conduit. The biggest problem is their toxicity by generating lamellar bone cells in the valvular leaflets, leading to calcification and making the leaflets stenotic and non-functional [6]. By en-large, the toxicity is dealt with using citric acid and the re-endothelialization method to develop the antithrombotic leaflet surface [7]. The perfusion method of decellularization is usually applied to remove the cells at particular time intervals without damaging the organ architecture (proteinaceous ECM) [11]. The left-behind ECM of the organ is utilized for re-cellularization by reperfusion of desired viable cells. Here the most significant challenge was endothelialization using host-specific HLA type or immunologically matched cells. It is a critical problem for the patients to get an immunologically HLA-matched donor for organs like the heart and valves for transplant in emergencies [8]. The donated and HLAmatched transplanted aortic valves are not always safe, as this may already have many hidden glitches, including virological infections (HIV, HCV, HBV) [9]. In the future, there will be a high demand for allogeneic or immunologically HLA-matched donor organs. This necessity can only be fulfilled by patient-specific humanization of the functional xenogeneic lab-grown organ [10]. Researchers have started developing a concept of decellularized bio-integrated valves from biological origins, which can be treated with various chemicals to increase their durability and compliance [12]. Currently, prosthetic valves have been developed worldwide in laboratories and companies (St. Judge's, Medtronic's, and Edward Life-sciences) [15]. Scientists have successfully developed various perfusion-based decellularized organs like the heart, lungs, kidney, livers, bladders [10,14] The perfusion technology for whole organ decellularization is exceptionally reliable. The advantage of this is the entire decellularization of the organ as the whole, including its various functioning parts, is beneficial for tissue engineering purposes.

As a complex modulator in various biochemical pathways, the vascular endothelium may be a critical element in the success rate in valve replacement surgeries. It is postulated that in-vitro establishment of an autologous endothelial lining of the prosthetic or biological valves would restore the physiological properties and thus improve the graft patency. An ideal artificial biomimetic aortic valve prosthesis should closely mimic a natural aortic valve in structure (mechanically) and function (metabolically). It should neither thrombose nor have inflammation with an occurrence of the valvular surface after implantation, resist degradation and adverse remodeling under various conditions. The lack of endothelial cells (ECs) on the surface of artificial graft contributes to thrombogenicity and calcification [16]. EC seeding on synthetic grafts has been attempted to mitigate these drawbacks, [17] and much work has been done with EC seeding on Dacron grafts. In-vivo studies on animals and recovery of EC lining have been investigated after implantation [18]. However, poor retention of ECs has been a significant problem. Therefore, various options to improve the adhesion and anchorage of ECs to conduits and scaffolds are obligatory.

In our study, we aim to evaluate whole organ perfusion-based decellularization and cross-linking (antigenicity masking) of aortic valves by glutaraldehyde reaction. Then we further proceeded towards the coating of the fabricated aortic valve leaflets with fibrin glue and re-endothelialization of wavy ECM surfaces.

Page 2/22 


\section{Materials And Methods Collection of sheep heart and dissection of aortic valves}

Sheep hearts (Group A) were collected from the local abattoir in sterile containers. They were immediately processed for surgical dissection and the sheep aortic valve (SAV) $(n=10)$. The hearts were cut to expose both the ventricular chambers and septum. The aortic valve region was traced by the aorta base ending into the mini aortic roots of ascending aorta. A fibrous structure known as the nodulus of Arantii can be seen towards the ventricular surface. The aorta was surgically cut from the peripheral region of the mini aorta base in a circular fashion. The aortic valve was removed successfully without any damage to the three parts of valve leaflets, such as dilated pockets of mini-aortic roots (Sinuses of Valsalva), semilunar-shaped cuspal free edges, and crescentic region termed lunula.

\section{Valves Groupings and processing}

The heart valves were randomly assigned into groups per the decellularizing agent and the method used, such as $0.2 \%$ Glutaraldehyde (Group $C$ ) ( $n=10$ ). In Group B ( $n=10)$, the whole heart was perfused with a mixture of $1 \%$ SDS and Triton-X 100. Group A ( $n=10)$, without any treatment, served as a control group. The details of the decellularization and cross-linking methodology are mentioned in Table.1.

\section{De-cellularization and Cross-linking of SAV samples}

Group A $(n=10)$ samples are not treated with any chemical and serve as the control. Group C (SAV) $(n=10)$ samples were decellularised by perfusion and crosslinked by $0.2 \%$ glutaraldehyde (GA) solution for seven days (Himedia, Mumbai, India). They were further neutralized by immersion in a $10 \%$ citric acid (Himedia, Mumbai, India) solution. [20, 21, 22, 23]

\section{Complete heart decellularization by perfusion technique and aortic valve dissection}

Sheep hearts $(n=10)$ were collected from a local abattoir after scarifying the animals in sterile conditions. The coronary perfusion method was used for the sheep heart decellularization. The pericardium was removed, and cannulation of the aorta and pulmonary artery was done. Approximately $500 \mathrm{ml}$ of $1 \mathrm{X}$ phosphate buffer saline was (PBS) perfused for four h through the aorta (aortic root coronary artery) and pulmonary artery simultaneously. lonic 1\% (SDS) (Himedia, Mumbai, India) was perfused for 11h, and non-ionic Triton-X100 (SRL, Mumbai, India) solvent was also infused for one h each day under the influence of gravity. The procedure continued until 12 days under continuous flow. The whole organ was found translucent and devoid of any red-colored blood vessels and blood cells. The aortic valve was removed, as mentioned above, from the mini aortic roots and rinsed in sterile deionized water for further testing.[10]

Picogreen dsDNA quantificatio $n$

The whole organ decellularized by the perfusion method was considered as Group B. Further, decellularised and cross-linked was served as Group C ( $0.2 \%$ $\mathrm{GA}$ ). An equal amount of the measured sample was taken to the lysis buffer, and the lysed samples were collected. A comparative Picogreen fluorescent biochemical assay quantified the total amount of dsDNA for confirming the presence of any residual cellular or tissue ds-DNA material left in the decellularized SAV groups. All the samples were compared with the Group A valve tissue leaflet [19].

\section{Histology for scaffolds and conduit by HE and Verhoeff's von-Gieson staining (EVG)}

All samples were fixed in $10 \%$ formaldehyde solution, sectioned at 5 microns size, and stained by hematoxylin-eosin (HE) for cellular localization. Verhoff's von-Gieson staining (EVG) was done for extracellular matrices (ECM) evaluation, such as elastin and collagen. The samples mentioned above were compared with Group A. Leaflet region examined were arterialis, fibrosa, spongiosa, and ventricularis under bright-field microscopy (Lynx Microsystems, Germany)[24]. Tensile Testing for Perfusion and cross-linked scaffolds

Conventional tensile measurements were performed using a tensile tester (Shimadzu AGS $500 \mathrm{G}$ ) with a load cell of $1 \mathrm{kN}$. The width of the sample was measured using a Vernier caliper. All samples $(n=10)$ were mounted between the Pneumatic holder's action grips. Tensile testing was conducted using a temperature-controlled bio-bath containing phosphate-buffered saline at a rate of $1 \mathrm{~mm} / \mathrm{min}$ maintained at a temperature of $37^{\circ} \mathrm{C}$. Young's modulus (in MPa) was automatically calculated. The slope of each stress-strain curve in its elastic deformation region was considered while calculating Young's modulus. The following parameters were studied: maximum load $(\mathrm{N})$, maximum stress $\left(\mathrm{N} / \mathrm{mm}^{2}\right)$, maximum displacement until total tear (mm), maximum strain until absolute tear (\%), Young's modulus (MPa), load at $10 \%$ elongation stress $\left(\mathrm{N} / \mathrm{mm}^{2}\right)$, and load at $20 \%$ elongation stress $\left(\mathrm{N} / \mathrm{mm}^{2}\right)$ [25].

\section{HUVEC isolation and culture}

Institutional Ethics Committee (IEC) approved informed consent from healthy persons for umbilical cord collection. The umbilical cord was collected aseptically after childbirth and processed in a tissue culture laboratory. The lumen of the umbilical vein was cleaned with sterile PBS 1X (Himedia) to remove blood clots. Collagenase (0.15\%) type IV (Sigma-Aldrich, USA) was used for dislodging the endothelial cells from the luminal cavity. The cord was incubated with the Collagenase solution for $20 \mathrm{~min}$ at $37^{\circ} \mathrm{C}$, and the luminal cells were harvested using DMEM (Sigma, USA). The cells in suspension were centrifuged at $1500 \mathrm{rpm}$ for $10 \mathrm{~min}$. The final cell pellet was re-suspended in endothelial growth medium (ECGM) (PromoCell, GmbH, Germany) containing $20 \%$ fetal sheep serum (FBS) (Invitrogen, Carlsbad, CA) and seeded on non-coated tissue culture plates (Falcon). After 12h of incubation, endothelial cells were supplied with complete ECGM containing $20 \%$ FBS, $2 \mathrm{mM}$ L- glutamine, and incubated at $37^{\circ} \mathrm{C}$ with $5 \% \mathrm{CO} 2$ [26].

\section{Tube formation assay in Matrigel for HUVECs}


Approximately $100 \mu \mathrm{l}$ of Matrigel (Corning, USA) per well was taken in a pre-chilled culture plate, avoiding bubble formation. Matrigel was allowed to polymerize at $37^{\circ} \mathrm{C}$ for one hour. HUVECs were starved for two hours before starting the assay and split to get approximately 100,000 cells/Matrigel-coated Petri-plates. The coated plate was incubated in an incubator, and capillary tube formation (angiogenesis) was observed $2 \mathrm{~h}-4 \mathrm{~h}$. Simultaneously, cultured smooth muscle cells (SMCs) were plated as a negative control to show the absence of tube formation [27].

\section{Cell seeding on decellularized scaffolds}

The decellularized scaffolds were seeded with HUVECs to make them a humanized form of aortic valve grafts. Group B $(n=10)$, Group C ( $n=10)$ frameworks were selected for HUVEC seeding and expansion.

\section{Phase-contrast for perfusion and SEM imaging}

Phase-contrast imaging was done for Group B $(n=10)$ scaffolds seeded with HUVECs for $48 \mathrm{~h}$. Further, SAV samples were fixed in $2.5 \%$ glutaraldehyde solution and washed with PBS 1X. Graded ethanol (30\%-100\%) were used for 10 min intervals for dehydration purposes. Further, SAV samples were treated with absolute acetone, and samples were evaporated to dryness and sputter-coated with gold (Quorum Technologies Ltd., UK) ${ }^{23}$. All the selected scaffold groups were coated with fibrin glue [34-35].

\section{Live dead Assay (FDA/PI)}

A live-dead assay for HUVECs expansion on the FG-coated scaffolds $(n=10)$ groups such as $B$, C, was done. FDA $5 \mu \mathrm{g} / \mathrm{ml}$ prepared in PBS-1X was used to stain the green fluorescence (viable cells) [28]. In contrast, propidium iodide (PI) was used at $2 \mu \mathrm{g} / \mathrm{ml}$ to stain red fluorescence (non-viable cells) on the valvular leaflet scaffolds $[34,35,36]$

\section{Cell viability assays}

MTT [3-(4,5-dimethylthiazol-2-yl)-2,5-diphenyltetrazolium bromide] (Himedia, Mumbai, India) (5 $\mu \mathrm{g} / \mathrm{ml})$ cell-based biochemical assay was performed for confirmation of HUVEC expansion on the surface of SAV scaffolds $(n=10)$ [29]. The results obtained were compared with normal HUVECs expanded on the tissue culture plate surface to the HUVECs grew on the valve leaflets surface. Approximately 100,000 HUVEC per valve leaflet was used for sodding on the scaffolds and conduits valvular surfaces $[34,35,36]$.

\section{Lycopersicon esculentum lectin expression}

HUVECs were fixed in $4 \%$ paraformaldehyde (Himedia, Mumbai, India) and further proceeded for Lycopersicon esculentum ${ }^{+/+}\left(\right.$lectin $\left.{ }^{+/+}\right)($Vector Labs, Burlingame, CA) expression. Re-endotheliazed Group B and Group C scaffolds ( $\mathrm{n}=10)$ were stained for Lycopersicon esculentum ${ }^{+/+}(\mathrm{FITC}$-conjugate) glycocalyx positive lectin molecular marker expression [33]. It is to confirm the HUVEC markers on re-cellularized Xenogeneic grafts to make them humanized valves. Further, Group B and Group C scaffolds were permeabilized with $50 \%$ chilled ethanol solution for 5 mins. Bovine serum albumin (BSA) $0.01 \%$ was used for non-specific binding (5 mins) prepared in PBS 1X. FITC-conjugate Lycopersicon esculentum ${ }^{+/+}$stain (lectin positive) developed 1:100 dilutions, and 2 $\mu \mathrm{g} / \mathrm{ml}$ were used to stain for $1 \mathrm{~h}$. Lectin positive expression was observed under the Zeiss, Apotome fluorescent microscope [34, 35].

\section{Endothelial universal marker expression}

For von-Willebrand factor (VWF) expression, HUVECs were cultured on coverslips and fixed using $4 \%$ paraformaldehyde. The cells were then treated with $50 \%$ chilled methanol for $5 \mathrm{~min}$ followed by $5 \%$ bovine serum albumin (BSA) for non-specific binding for $1 \mathrm{~h}$. HUVECs were targeted to Anti-von-Willebrand factor (vWF) primary non-labeled antibody IgG fraction of antiserum developed in rabbit (1:200 dilution) (Chemicon, Temecula, CA) for $16 \mathrm{~h}$ at $4{ }^{0} \mathrm{C}$, followed by respective secondary antibodies (Invitrogen, Carlsbad, CA) for $2 \mathrm{~h}$ at $37^{\circ} \mathrm{C}$. The coverslips were mounted in anti-fade (Vectashield, Vector Laboratory, Burlingame, CA) and 40, 6-diamidoino- 2-phenylindole (DAPI) (Invitrogen, Carlsbad, CA). The slides were signaled on an LSM 510 Zeiss workstation confocal laser scanning microscope (Carl Zeiss Meditec AG, Jena, Germany) [36]. The vWF expression was indicated for HUVECs in culture and on Group B and Group C scaffolds.

\section{Statistical Analysis}

Graph Pad Prism 5 software was used for statistical analysis (Mean \pm S.D), and the One Way-ANOVA test for the level of significance $* \star \star P<0.05$ was performed by Dunnet test.

\section{Results}

Morphological alterations in processed samples.

The complete organ (sheep heart, Fig. 1A) decellularization (Group B) by perfusion technique resulted in a change of coloration from dark reddish to pinkish (Fig. 1B) and finally translucent (whitish) (Fig. 1C). The occurrence of fatty tissue patches scattered in various epicardium regions was observed. The branching of coronary vessels and other vasculature architecture can be easily visualized (Fig. 1C). Surgical dissection of the aortic valve (Fig. 1E) revealed that the internal structures have been entirely devoid of cells with clear demarcation of whitish and pinkish appearance in the endocardium and myocardium region (morphologically). Group B samples became white-pinkish translucent in appearance and soft (Fig. 1E) in comparison to Group A sample (Fig. 1D). Group C (Fig. 1F) example provided durable robust-rubbery texture after cross-linking and neutralizing in contrast to Group A sample. GA (0.2\%) and citric acid $(10 \%)$ exposures to aortic valves resulted in a stable, insoluble biomaterial with superior resistance to proteolytic degradation (Fig. 1F).

\section{Histological, DNA, and mechanical examination of the valves}


The histological investigation of the valves made a clear distinction in the leaflet region of arterialis, fibrosa, spongiosa, and ventricularis. VECs (valvular endothelial cells) and VICs (valvular interstitial cells) stained with dark blue-black nuclei along with pinkish cytoplasm were observed in the background in all the different regions of SAV (Fig. 2A). ECM was evaluated by EVG staining for the detection of collagen (Red) and elastin (yellow) in the various areas of the leaflet (Fig. 2D). For Group B and Group C, the cells were absent from the arterialis, fibrosa, spongiosa, and ventricularis leaving behind the matrix (Fig. 2B). Elastin and collagen examination (EVG) for Group B (Fig. 2E) and Group C (Fig. 2F) demarcated the occurrence of an intact extracellular matrix devoid of cells (Table.2).

Group B $(-1.267 \mathrm{ng} / \mathrm{ml} \pm 0.2082)$ and Group C (-1.367 ng/ml \pm 0.2082) valvular leaflets showed the absence of host-specific DNA, in contrast to Group A (6777 $\mathrm{ng} / \mathrm{ml} \pm 195.4$ ), which showed a clear presence of DNA. The lack of ds-DNA helped us select the scaffold for further endothelial cell expansion studies (Fig. 3). The values of the different parameters were calculated from the stress vs. strain curves for the respective valves and plotted for the individual groups (Fig. 4). The maximum load (Fig. 4A) for Group A (4.200 N \pm 0.1000$)$ was higher than Group B (3.073 N \pm 0.06429$)$. There was an extreme fold increase in maximum load for Group C $8.303 \mathrm{~N} \pm 0.4416$ (Fig. 4A) in comparison to Group A and Group B. Maximum stress (Fig. 4B) in case of Group B (0.002333 N/mm² \pm $0.001528)$ and Group $C\left(0.02233 \mathrm{~N} / \mathrm{mm}^{2} \pm 0.001155\right)$ is lesser than the Group $A\left(0.03533 \mathrm{~N} / \mathrm{mm}^{2} \pm 0.002517\right)$. Maximum displacement till total tear (mm) (Fig. 4C) for Group A (16.73 mm \pm 0.5508$)$ was higher in comparison to Group B (12.00 mm \pm 0.1000$)$. Cross-liking robust material that is Group C maximum displacement till total tear (18.20 mm \pm 0.2646$)$ was higher in comparison to Group A. Maximum strain till complete tear (\%) (Fig. 4D) for Group A (34.23\% \pm $0.04933)$ was more near to Group $B(33.42 \% \pm 0.1582)$. There was an increase in maximum strain for Group C (55.29 \% \pm 0.1677$)$ in comparison to Group A. The young's modulus (elasticity) (Fig. 4E) in the event of Group A (3.067 MPa \pm 0.05773 ) is higher compared to Group B (0.1233 MPa \pm 0.01528 ). Group C (3.750 MPa \pm 0.05291 ) is rigid compared to Group A (Fig. 4E), and the load required to deform it is pretty high compared to control. Load at Specified Elongation Stress [LASE 1] (at 10\%) (N/mm²) was higher for Group A (Fig. 4F) in comparison to Group B and Group C similarly nearly comparable was obtained for LASE 2 (at $20 \%)\left(\mathrm{N} / \mathrm{mm}^{2}\right)(4 \mathrm{G})$ to LASE 1 (Table.3).

\section{Isolation, culture, and functional characterization of HUVECs}

To re-endothelialize the decellularized valves as a source of endothelial cells, we used HUVECs. Approximately 20 cobblestone clusters were seen on 0 days of HUVECs seeding while expanding in clusters (Fig. 5A). Further, the expansion was in the form of clonal clusters of cobblestone (Fig. 5B). On day $10^{\text {th, }}$ complete pebble shape HUVECs with uniform colonies were seen in culture (Fig. $5 \mathrm{C}$ ). On day $12^{\text {th, }}$ more than $80 \%$ of the cell culture plate was occupied by the HUVECs with a tiny uniform cobblestone phenotype with grassland crop circles (Fig. 5D). On day $12^{\text {th, }}$ the HUVECs reached approximately $3.5 \times 10^{5}$ cells/well. The functionality of HUVECs was assessed by angiogenic matrigel assay. About $3 \times 10^{5}$ HUVECs/well were seeded, and capillary generation (angiogenesis- was observed after 1h, 3h, $4 \mathrm{~h}$, $6 \mathrm{~h}$ of incubation in the Matrigel-coated well. HUVECs showed sprouting like elongated tubes without forming deformities (Fig. 6).

\section{Reendothelialization of the valves and characterization of the endothelial layer.}

Following the above functional characterization of HUVECs, we proceeded to re-endothelialization the valves. After layering HUVECs on the valves, phasecontrast images for Group B showed maximum expansion of HUVECs onto the leaflet surface with a monolayer of proliferating cells in $48 \mathrm{~h}$ with changing their phenotype as per the scaffold structure and consistency (Fig. 7A). To further assess the endothelial layer of the valve, we employed SEM imaging. The SEM imaging for Group A shows valvular endothelial cells (VEC) on the aortic valve leaflet (Fig. 8A). Group B valvular leaflet explains the absence of VECs with only fragmented and crumpled decellularized matrix surface (Fig. 8B). The knitted meshwork of fibrin glue (FG) coating on the valvular leaflet surface is observed on the Group B (Fig. 8C) and Group C (Fig. 8D) matrix, which is devoid of cells. FG coated Group B (Fig. 8E), Group C (Fig. 8F) showed the expansion of HUVECs in $48 \mathrm{~h}$ with a clear orientation of re-endothelization on the leaflet scaffold surface and their further expansion. The HUVECs aligned as per the matrix texture parallel (Fig. 8E and Fig. 8F) due to valvular leaflet surface interaction with turgor blood propulsion.

To assess the viability of the cells, we used a live-dead cell assay. The negative control showed non-fluorescence (Fig. 9A). Maximum green fluorescence (FDA) staining was observed in large patches for Group B scaffolds (Fig. 9B) due to the fusion of HUVECs to form a sheet-like phenotype. Group C scaffolds showed endothelial cells in speckled clusters, as seen in Group C scaffolds (Fig. 9C). The re-endothelization and cell viability were observed for both frameworks (Group B and Group C).

To further characterize the endothelium at the molecular level, we tested the expression of typical endothelial markers. The cultured HUVECs expressed Lycopersicon esculentum $^{+/+}$(lectin) (Fig. 10B). Further, expanded HUVECs on the Group B scaffolds showed the endothelial-specific phenotypic positive glycocalyx expression for FITC-labeled Lycopersicon esculentum ${ }^{+/+}$(lectin) (Fig. 10C). The lectin positive glycocalyx expression was expressed in scattered and large patches throughout the Group C scaffolds (Fig. 10D). Negative control did not show any expression (Fig. 10A). Further, to examine the identity of HUVECs, we studied vWF positive expression in culture. Control cells confirmed the presence and homogenous nature of the EC-specific marker vWF in the cytoplasmic area of the cells in Weibel Palade bodies (WPBs) (Fig. 10F). Enhanced vWF signals were detected on Group B (Fig. 10E) and Group B (Fig. 10F) valvular leaflets, further confirming the endothelial nature of the cellular layer.

\section{Biochemical assay for (cellular viability and Proliferation) on the scaffolds}

Further characterization of the viability of the endothelium of the valves was achieved by MTT assays. In culture, the viability of HUVECs was $69.57 \% \pm 1.277$. Group A valvular leaflet was subjected to formazan crystal formation, and viability for cells present was $98.20 \% \pm 0.9050$. HUVECs are cultured for about $72 \mathrm{~h}$ on the scaffolds, such as Group B $(92.38 \% \pm 2.407)$, Group C $(91.27 \% \pm 2.060)$. Interestingly, the above data suggest that Group B and Group C fabricated scaffolds support the endothelial cell proliferation to develop a non-thrombotic floor (Fig. 11). 
The limitations of the bioprosthetic transplant are well known. It can lead to complications like calcification, malfunctioning of leaflets (valvular stenosis), arrhythmias, biological deterioration, and infection [2]. The problem of aortic valve calcification causing valvular dysfunction is currently a significant challenge to both scientists and surgeons. Approaches have been made to deal with the calcification to develop a tissue-engineered valve by treatment with $70 \%$ ethanol because ethanol plays an essential role in anti-calcification [23]. It is a great challenge to create an entirely functional, low-immune, and sustainable tissue-engineered aortic valve. Significant problems like tissue calcification, graft versus host reaction are responsible for a heart valve implant rejection. It could be reduced by optimizing the technique for decellularizing the valve tissues, keeping ECM intact, and re-cellularizing with patient-specific endothelial cells to fabricate a low-immune, humanized xenogeneic heart valve. We have re-defined a protocol to structure a tissue-engineered biological aortic valve from sheep sources, showing responsive and self-renewing properties like graft bio-integration without inflammation if implanted in future models.

We observed that the perfusion-based whole organ decellularization (sheep heart) is the most effective way to retrieve perfectly decellularized aortic valves (situated at the base of the mini aortic roots of the aorta). The decellularization process started from both the auricles on day two with continuous perfusion of $1 \%$ SDS solution followed by $1 \%$ Triton-X 100 solutions. Whole organ decellularization was achieved in 12 days (Group B). Later, Group C was subjected to a similar protocol of decellularization followed by cross-linking with $0.2 \%$ glutaraldehyde, followed by $10 \%$ citric acid. Group $\mathrm{C}$ (cross-linked sample) was selected because this technique is highly used and applied by cardiothoracic surgeons $[5,15]$. Preparation of valvular conduit by cross-linking using aldehyde polymer $(0.2 \% \mathrm{GA})$ and further neutralizing its toxic effect by treating with $10 \%$ citric acid leads to better cellular affinity and adherence towards ECM of the conduit surfaces $[7,23]$.

Both the heart auricles and ventricles showed slowly progressive decellularization with changing color from light pink to finally crystal clear in $48 \mathrm{~h}$. All the vasculature networks, coronary, and circumflex arteries, veins, and the aorta and pulmonary arteries became colourless and translucent. Some of the fatty patches were observed in the ventricular regions, which gave a mosaic impression. Surgical dissection of aortic valves from the mini aortic roots also showed a translucent appearance of the valvular leaflets with intact ECM structure and morphology. Group $\mathrm{C}$ samples gave a robust and rubbery nature. The $10 \%$ citric acid treatment added a sticky quality to the scaffold [7].

Histology for both Group B and C examination showed all the cardiac zones (epicardium, myocardium, and endocardium) with a complete absence of cellular materials. At the same time, Group A acted as a control. EVG staining of both groups (B and C) showed the yellow color of elastin in arterialis and fibrosa region and dark red color collagen in the ventricularis area under a bright field microscope. EVG staining for Groups B (Fig. 2E) and C (Fig. 2F) showed that aortic valve leaflet scaffold ECM was excellently preserved without damaging the texture and architecture. Basophilic nuclei were observed in Group $A$ (Fig. 2A) by EVG staining in all regions (Fig. 2D). HE staining examination for aortic valve and its leaflets scaffolds resembled the complete absence of cells (basophilic nuclei) in arterialis and fibrosa (VECs, spongiosa-VICs fibroblast, and smooth muscle-like cells, VECs). It established that 1\% SDS (Fig. 2B) supports the maximum removal of cells from various cardiac locations. Histological examination again confirmed the preservation of all the ECM structures in all the regions of the valves leaflets. It supports that GA has excellent matrix fixation and preservation properties to reduce post-mortem changes. ${ }^{5} \mathrm{GA}$ in $0.2 \%$ concentration and its neutralization by $10 \%$ citric acid enhances the hydrophilic character of the leaflet surface. GA, due to its antifungal and antibacterial properties, ensures excellent sterilization [24]. It reacts chemically with the aortic valves and leaflet surfaces through free aldehydes monomeric or polymeric glutaraldehyde. Its action is primarily on amines groups of lysine, hydroxylysine, or N-terminal amino acid residues, which are present in the ECM. The reaction gives a Schiff base product, which is stable at physiological temperature and $\mathrm{pH}$. [5, 7]. It has a mechanism of masking the antigenic sites over the leaflet tissue surfaces through converting leaflets' ECM protein into insoluble cross-linked structures, thus, enhancing the resistance to proteolytic degradation [5, 23]. GA reacted covalently with the collagen present in the ECM of the leaflets when they were cross-linked for seven days.

Further, acellularity was confirmed by various assays. DNA quantitation by Pico green showed variation in the level of residual DNA (Fig. 3) in all groups. It explained that Group A showed the highest DNA compared to Group B and C, where there was an absence of DNA. Pico green DNA quantitation provided excellent results for the presence of significantly less DNA.

The host tissue genetic and cellular material is primarily significant, as they play a role in graft rejection after allogeneic cell expansion on the graft or after invivo implantation. We further chose perfusion-based decellularized scaffold and cross-linked groups (B and C) for HUVEC expansion onto the leaflet surfaces. We re-endothelialized valvular scaffold surfaces to develop a biocompatible, biomimetic, and completely functional tissue-engineered graft. The endothelialized surface provides a non-thrombogenic surface during the blood flow. The main hurdle in this bioprosthesis is sustaining the cells on the graft after transplant. Usually, the sheer force of the blood flow sheds off the seeded endothelial cells from the implant. The denuded area becomes the new site for clot formation and leads to well-known complications. We dealt with this issue by applying fibrin glue (FG) prepared from sheep blood to the scaffold before seeding the HUVECs (Fig. 8C). FG plays a significant role as a natural sealant and even acts as a biological meshwork scaffold that can entrap the seeded endothelial cells and support their bio-integration with the leaflet surfaces. ${ }^{23}$ We seeded 0.1 million HUVECs per valvular leaflet [Group B and Group C (FGcoated)] surfaces (Fig. 8E) and (Fig. 8F). The phase-contrast microscopic analysis supported that perfusion-based decellularization sustains the HUVEC expansion (Fig. 7), and an entirely tissue-engineered monolayer leaflet was developed within 48h. It proved that endothelial cells get organized excellently with the scaffold leaflets as per scaffold texture. The images (Fig. 8E and Fig. 8F) depicts HUVECs aligning in all parallel orientation according to the native biomimetic leaflets, thus proving their remodeling as per the required scaffold texture.

Further, to check whether Group B and Group C developed scaffolds support the HUVECs expansion, we carried out a metabolic cell proliferation (MTT) assay (Fig. 11). HUVECs proliferation was enhanced for both Group B and C scaffolds. The dark blue color of formazan crystal formation was noted along the entire area of the leaflet surface (Fig. 11). However, the formazan crystal formation for Group B and Group C scaffold was more than HUVECs in culture (Fig. 11). The findings were paralleled in some decellularization and scaffolding experiments with other tissues such as tendons and arteries, which are tubular and thinner in size [31-32]. 
Re-endothelialization after seeding the endothelial cell was maximum for Group B and Group C scaffold compared to culture cells. SEM analysis for Group B (Fig. 8E) and Group C (Fig. 8F) revealed the HUVECs expand in clusters and also in a parallel orientation similar to that of Group A (Fig. 8A).

Live-dead assay for Group B (Fig. 9B) and Group C (Fig. 9C) scaffolds showed denser patches of live cells onto the leaflet surfaces after 48h showing endothelial cell adhesion and expansion. It demarcates that Group B and Group C scaffolds support the HUVECs adhesion on FG coated surfaces and maintain their viability to make them proliferate and re-endothelialize.

Molecular marker glycocalyx lectin (Lycopersicon esculentum) positive expression emphasized that the HUVECs (Fig. 10B) do not lose their character in culture as well as on the Group B (Fig. 10C) and Group C (Fig. 10D) scaffold during their development as it is essential to note that primary culture of HUVECs generally alter their phenotype after five subculture or attain contact inhibition and change their characters. However, we examined that ECM supports the endothelial cells on the FG-coated matrix to maintain their phenotype. Isolated HUVECs were cultured from 0 days to the 12 th day. At 0 days, HUVECs resemble bunches of the cluster and start flattening their pseudopodia to establish adherence (Fig. 5A). HUVECs started clone formation in cultures in cobblestone fashion (Fig. 5B). On day 10th HUVECs reached the almost entire zone of culture plate surface (Fig. 5C). The whole grassland-like crop circles were observed infinity-like in HUVECs after achieving the 12th day (Fig. 5D). After attending the confluence, the HUVECs were trypsinized and further progress for angiogenesis matrigel assay. Matrigel assay showed that HUVECs expanded to develop into angiogenic capillary-like tube formation (Fig. 6). HUVECs seeded showed HUVECs remodeling towards angiogenic morphology as the time progressed. For 1h, HUVECs resemble pebble shape clusters (Fig. 6A and Fig. 6 E). For 3h (Fig. 6B andFig.6F) and 4h (Fig. 6C and Fig. 6G), there was a proper capillary network generation on the matrigel. The tube formation showed a decline at $6 \mathrm{~h}$ (Fig. 6D and Fig. $6 \mathrm{H}$ ). Matrigel assay revealed that the endothelial cells maintain their angiogenesis state. As we are familiar that endothelial cells alter their molecular marker expression in culture if not appropriately maintained. von-Willebrand factor (vWF) is a multimeric glycoprotein essential for the routine arrest of bleeding after tissue injury (homeostasis). The molecule is present in endothelial cells (ECs), blood (plasma and inside platelets), and the sub-endothelial matrix of the vessel wall [23]. Here, we expanded HUVECs on the valvular leaflet scaffolds and maintained them till they re-endothelialized the leaflet surface, and we targeted vWF antibody to examine the VWF positive signal. It was interesting to report that we obtained an enhanced signal for vWF ${ }^{+/+}$ on the entire valvular leaflet surface (Fig. 10G and Fig. 10H) both the scaffolds (Group B and Group C). It was evident that HUVECs did not alter the vWF expression if expanded on the bioprosthesis. Simultaneously we also examined the $\mathrm{VWF}^{+/+}$for the HUVECs in culture (Fig. 10F), which supported us in identifying the $\mathrm{VWF}^{+/+}$signals on valvular leaflets.

The mechanical properties in Group A depict standard valve features, whereas those of the perfused samples are the ones that are devoid of cells (Fig. 4A-B). lonic chemical detergent (SDS) treated Group B, and cross-linked mode decellularized scaffolds such as Group $C$ showed variation in the level of robustness. Group $A$ is stiffer and more force is required to deform it compared to the perfused heart. 1\% SDS (Group B) causes the cells to be dislodged from the matrix, and further cross-linking with GA (Group C) makes it rigid. The perfused and cross-linked whole heart (Group C) are closest to the control (Table.3 and Fig. 4).

Our study proved that perfusion-based decellularization (1\% SDS + triton X 100 protocol) provides maximum decellularization. But, maintaining the mechanical strength was an issue, which was rectified using $0.2 \%$ Glutaraldehyde. The toxicity of the GA is neutralized by $10 \%$ citric acid. The treatment with GA enhanced the lost mechanical strength, which was caused by decellularization. It was found that perfusion-based Group B and C provided excellent decellularization with preservation of ECM texture and architecture of the entire organ, which hopefully supports the growth and expansion of the desired cells. Another advantage of perfusion technology is that we can get entirely decellularized organs by using ionic chemical detergents with a specific concentration solvent gradient. Even though the whole organ is not required for tissue engineering, we can utilize its various precious functioning parts for tissue engineering applications like valves, coronary arteries, aortas, pulmonary arteries, pericardium, etc. Re-endothelialization with self-cells is an ideal way to transform a scaffold into a biologically accepted graft. As sustaining the cells on the scaffold in-vivo while facing the sheer pressure of blood flow is a task, we utilized the advantage of fibrin glue. The only limitation of the perfusion-based decellularization is that it is time-consuming and takes a few days to get decellularized and again re-cellularized to structure a viable, sustainable, low-immune implant.

\section{Conclusion}

This study showed a comparative approach between decellularization processes and further cross-linking (glutaraldehyde polymer) for aortic valves to fabricate low immunogenic and sterile grafts. The re-endothelization technique on the perfusion-based whole organ decellularization of the aortic valve enhanced the patency (metabolically) with improved compliance. Further, cross-linking of decellularized aortic valve leaflets scaffold masks the antigenicity with improved acceptability for implantation. This perfusion-based decellularised and cross-link scaffolds also maintains vWF expression on valvular leaflet matrix without altering their phenotype. The concept of re-endothelialization on decellularized and cross-linked aortic valve leaflet leads to a non-thrombotic and biocompatible vascular prosthesis.

\section{Declarations}

\section{Acknowledgment}

We kindly acknowledge HEAL ${ }^{\mathrm{TH}}$ BIOLABS staff for providing us with the laboratory facilities.

Data Availability: The availability of data and material has been described in the manuscript. They are freely available to any scientist who wishes to use them without breaching participant confidentiality.

\section{Disclosures}

Conflict of Interest Declared: Authors do not have any financial or professional conflict of interest. 


\section{Funding}

This study is supported by the research grant in aid received from HEAL ${ }^{\text {TH }}$ BIOLABS, Kolhapur, India, and Shree Hospital \& Research Institute (SHRI) Kolhapur, India.

\section{Institutional Ethics committee approval and informed consent}

Prior permission of the Institutional ethics (HBL-SHREC) committee was obtained to collect sheep hearts from local abattoirs. Intuitional ethics (HBL-SHREC) committee approval, as well as patients' informed consent, was obtained for collection of the discarded umbilical cord after parturition as per the principles outlined in the declaration of Helsinki.

Author contributions: SW and SA designed the study. SW and SA carried all the experiments. SW and SA analyzed all the results data. SW and SA interpreted the results and wrote the manuscript. SA advised on manuscript content and communications. All authors' approval of the final version of the manuscript to be published. SC provided study design inputs during the research. SNR also provided study design inputs.

\section{References}

1. D A Towler. Molecular and Cellular Aspects of Calcific Aortic Valve Disease. Circ. Res. 2013; 113: 198-208. doi:10.1161/CIRCRESAHA.113.300155.

2. A Bader, T Schilling, O E Teebken, G Brandes, T Herden, G Steinhoff, A Haverich. Tissue engineering of heart valves--human endothelial cell seeding of detergent acellularized porcine valves. Eur. J. Cardio-Thorac. Surg. Off. J. Eur. Assoc. Cardio-Thorac. Surg.,1998; 14: $279-284$.

3. Almelkar S I, Divate S, Patwardhan A M. Bacopa monniera herb as an antioxidant in reducing lipid peroxidation levels in cultured human endothelial cells. Journal of Cell and Tissue Research.2013; 13(1): 3549-3556.

4. D S Hui, DM Shavelle, M J Cunningham, RV Matthews, V A Starnes. Contemporary use of balloon aortic valvuloplasty in the era of transcatheter aortic valve implantation, Tex. Heart Inst. J. Tex. Heart Inst. St. Lukes Episcop. Hosp. Tex.Child. Hosp., 2014; 41:469-476. doi:10.14503/THIJ-13-3757.

5. T Kaneko, L H. Cohn, and Sary F. Aranki. Tissue Valve Is the Preferred Option for Patients Aged 60 and Older. Circulation. 2013; 128:1365-1371

6. B A Carabello. Introduction to Aortic Stenosis. Circ. Res.,2013; 113: 179-185. doi: 10. 1161 / C I R CRESAHA .113.300156.

7. H Gulbins, A Pritisanac, K Pieper, A Goldemund, BM Meiser, B Reichart, S Daebritz. Successful endothelialization of porcine glutaraldehyde-fixed aortic valves in a heterotopic sheep model. Ann. Thorac. Surg. 2006; 81: 1472-1479. doi:10.1016/j.athoracsur,2005,11.011.

8. M P Chacko, A Mathan, D Daniel, G Basu, S Varughese. Significance of pre-transplant anti-HLA antibodies detected on an ELISA mixed antigen tray platform. Indian J. Nephrol., 2013; 23, 351-353. doi:10.4103/0971-4065.116303.

9. S K Agarwal, S C Tiwari. Efficacy and tolerability of lamivudine in hepatitis B infected renal transplant recipients: A single-center study, Indian J. Nephrol.,2009;19: 91-95. IP: 218.248.6.153

10. H C Ott, T S Matthiesen, S K Goh, L D Black, S M Kren, T I Netoff, D A Taylor. Perfusion decellularized matrix: using nature's platform to engineer a bioartificial heart. Nat. Med.,2008; 14: 213-221. doi:10.1038/nm1684.

11. X Ren, H C Ott. On the road to bioartificial organs. Pflüg. Arch. Eur. J. Physiol.,2014; 466: 1847 1857. doi:10.1007/s00424-014-1504-4.

12. DC Sullivan, S H Mirmalek-Sani, D B Deegan, PM Baptista, T Aboushwareb, A Atala, J J Yoo. Decellularization methods of porcine kidneys for whole organ engineering using a high-throughput system, Biomaterials. 2012, 33: 7756-7764.

13. P M Baptista, M M Siddiqui, G Lozier, S R Rodriguez, A Atala, S Soker. The use of whole organ decellularization for the generation of a vascularized liver organoid. Hepatol. Baltim. Md.,2011; 53: 604-617.

14. A Atala. Tissue engineering of the human bladder. Br. Med. Bull.,2011; 97: 81-104.

15. W B Eichinger, I M Hettich, D J Ruzicka, K Holper, C Schricker, S Bleiziffer, R Lange. Twenty-year experience with the St. Jude medical Biocor bioprosthesis in the aortic position, Ann. Thorac. Surg.,2008; 86 1204-1210.

16. P Zilla, D Bezuidenhout, P Human. Carbodiimide treatment dramatically potentiates the anticalcific effect of alpha-amino oleic acid on glutaraldehydefixed aortic wall tissue. Ann. Thorac. Surg. 79, 2005; 905-910.

17. A Lerman, A M Zeiher. Endothelial function: cardiac events. Circulation,2005; 111: 363-368.

18. A Ketchedjian, A L Jones, $P$ Krueger, E Robinson, $K$ Crouch, $L$ Wolfinbarger, $R$ Hopkins. Recellularization of decellularized allograft scaffolds in ovine great vessel reconstructions. Ann. Thorac. Surg. 79, 2005; 888-896; discussion 896.

19. S N Rath, L A Strobel, A Arkudas, J P Beier, A K Maier, P Greil, R E Horch, U Kneser. Osteoinduction and survival of osteoblasts and bone marrow stromal cells in 3D biphasic calcium phosphate scaffolds under static and dynamic culture conditions. J. Cell. Mol. Med.,2012; 16: 2350-2361. 
20. B Ma, X Wang, C Wu, J Chang. Crosslinking strategies for the preparation of extracellular matrix-derived cardiovascular scaffolds, Regen. Biomater.,2014; 1: $81-89$.

21. Francesco Moroni, Teodelinda Mirabella, Decellularized matrices for cardiovascular engineering. Am J Stem Cells.,2014; 3 (1): 1-20

22. PM Crapo, TW Gilbert, S F Badylak. An overview of tissue and whole organ decellularization processes. Biomaterials.2011; 32: 3233-3243.

23. Almelkar SI, Kadam SS, Diwate S, Chaukar A, Bhonde RR, Patwardhan AM. Re-endothelialization of biological tissue-engineered conduits and scaffold for its potential use in bioprosthesis. OA Tissue Engineering 2013 Mar 01; 1(1):1-6.

24. Lynch, Matthew J. Medical Laboratory Technology. Volume 1. Philadelphia: W.B. Saunders Company, United States. RB37.

25. Patwardhan Anil Madhav, Vaideeswar Pradeep. Stress-strain characteristics of glutaraldehyde treated porcine aortic valve tissue following ethanol treatment. IJTCVS., 2004; 20: 67-71.

26. B Baudin, A Bruneel, N Bosselut, M Vaubourdolle. A protocol for isolation and culture of human umbilical vein endothelial cells. Nat. Protoc.,2007; 2: 481485.

27. G Taraboletti, R Giavazzi. Modelling approaches for angiogenesis, Eur. J. Cancer Oxf. Engl., 1990, 40 (2004); 881-889.

28. J A Cardella, S Keshavjee, E Mourgeon, S D Cassivi, S Fischer, N Isowa, A Slutsky, M Liu. A novel cell culture model for studying ischemia-reperfusion injury in lung transplantation, J. Appl. Physiol. Bethesda Md, 1985; 89 (2000); 1553-1560.

29. Shetty S S, Kaushik S S, Mojamdar M M, Gogate A A, Chaukar A P. Viability testing of homograft valves using methyl thiazol tetrazolium assay. J Postgrad Med., 1996; 42: 72-5.

30. Xu H, Xu B, Yang Q, Li X, Ma X, et al. Comparison of Decellularization Protocols for Preparing a Decellularized Porcine Annulus Fibrosus Scaffold. PLoS ONE, 2014; 9(1): e86723.

31. Badylak S F. The extracellular matrix as a biologic scaffold material. Biomaterials, 2007; 28: 3587-93.

32. Uriel S, Labay E, Francis-Sedlak M, Moya ML, Weichselbaum RR, et al. Extraction and assembly of tissue-derived gels for cell culture and tissue engineering. Tissue Eng Part C Methods. 2009; 15: 309-21.

33. Cecile J Favre, Michael Mancuso, Kevin Maas, John W McLean, Peter Baluk, and Donald M. McDonald. Expression of a gene involved in vascular development and angiogenesis in endothelial cells of adult lung. Am J Physiol Heart Circ Physiol., 2003; 285: H1917-H1938

34. Walawalkar S, Almelkar S. Fabrication of aortic bioprosthesis by decellularization, fibrin glue coating, and re-endothelization: a cell scaffold approach. Prog Biomater, 2019; 8: 197-210

35. Walawalkar S, Verma M K, Almelkar S. Re-endothelization of human saphenous vein scaffold surfaces for bioprosthesis fabrication. Journal Biomaterials Applications. 2020; 34(8): 1081-1091.

36. Walawalkar S, Almelkar S. Fabricating a pre-vascularized large-sized metabolically supportive scaffold using Brassica oleracea leaf. Journal of Biomaterials Applications. 2021; 36(1), 165-178.

\section{Tables}

Table 1. The table describes Groups A (control samples), Groups B (perfused whole heart valves), C (Perfused+cross-linked samples). Various parameters were analyzed for these groups, such as Histology(HE \& EVG), Picogreen (DNA quantification), Tensile testing, FDAPI (Live dead assay), phase contrast microscopy, MTT assays. 
SAV Grouping: Table. 1

\begin{tabular}{|c|c|c|c|c|c|}
\hline Groups & Solvents & $\begin{array}{l}\text { Sample } \\
\text { type }\end{array}$ & $\begin{array}{l}\text { Time or Days } \\
\text { (decellularization) }\end{array}$ & Temperature & Experiments \\
\hline \multirow{2}{*}{$\begin{array}{l}\text { Group } \\
\text { A }\end{array}$} & \multirow{4}{*}{$\begin{array}{l}\text { Control } \\
\text { ( No treatment) }\end{array}$} & \multirow[t]{4}{*}{ SAV } & \multirow[t]{4}{*}{ Nil } & Room & Histology (HE \& EVG) \\
\hline & & & & Temperature & $\begin{array}{l}\text { Picogreen (DNA } \\
\text { quantification) }\end{array}$ \\
\hline \multirow[t]{2}{*}{$(n=10)$} & & & & & Tensile testing, SEM, \\
\hline & & & & & MTT \\
\hline \multirow{4}{*}{$\begin{array}{l}\text { Group } \\
\text { B }\end{array}$} & \multirow{6}{*}{$0.01 \%$ SDS } & \multirow{6}{*}{ SAV } & \multirow{6}{*}{$15 \mathrm{~h}$} & \multirow{6}{*}{$37^{0} \mathrm{C}$} & Histology (HE \& EVG) \\
\hline & & & & & $\begin{array}{l}\text { Picogreen (DNA } \\
\text { quantification) }\end{array}$ \\
\hline & & & & & Tensile testing \\
\hline & & & & & FDA/PI (Live dead assay) \\
\hline \multirow[t]{2}{*}{$(n=10)$} & & & & & SEM \\
\hline & & & & & MTT \\
\hline \multirow{4}{*}{$\begin{array}{l}\text { Group } \\
\text { C }\end{array}$} & \multirow{6}{*}{$\begin{array}{l}1 \% \text { SDS +Triton-X } 100+0.2 \% \text { Glutaraldehyde } \\
(\mathrm{GA})\end{array}$} & \multirow{6}{*}{ SAV } & & & Histology (HE \& EVG) \\
\hline & & & 12days & & $\begin{array}{l}\text { Picogreen (DNA } \\
\text { quantification) }\end{array}$ \\
\hline & & & $\begin{array}{l}\text { [Crosslinking: } 24 \mathrm{~h} \times 7 \\
\text { days] }\end{array}$ & $37^{0} \mathrm{C}$ & Tensile testing \\
\hline & & & & & FDA/PI (Live dead assay) \\
\hline \multirow[t]{2}{*}{$(n=10)$} & & & & & SEM \\
\hline & & & & & MTT \\
\hline
\end{tabular}

Table 2. HE and EVG staining investigations were carried for perfusion (Group B) and perfusion + crosslink groups (Group C). 
Table. 2

Group A Sample Histological details for HE staining (Fig. 2A)

Histological details for EVG sta

\begin{tabular}{|c|c|}
\hline Arterialis & Fibrosa \\
\hline $\begin{array}{l}\text { Valvular } \\
\text { endothelial cells } \\
\text { (VECs) }\end{array}$ & $\begin{array}{l}\text { Valvular } \\
\text { endothelial cells } \\
\text { (VECs), }\end{array}$ \\
\hline
\end{tabular}

Spongiosa

Ventricularis

Arterialis

Valvular interstitial Valvular endothelial cells

cells (VICs) (VECs)

resemble fibroblast

and smooth

muscle-like

Connective tissue cells

Elastic fibers are observed in the basal region of cups as a

Control

$$
\text { SAV }
$$

$(n=10)$

Connective

tissue

cells(fibroblast

myofibroblast)

Fibroblastic cells,

myofibroblast, Typical smooth

muscle-like cells.

Complete Sheep Heart Decellularized by Perfusion Method

\begin{tabular}{|c|c|c|c|c|c|c|}
\hline \multirow{2}{*}{$\begin{array}{l}\text { Group B } \\
\text { Whole organ } \\
\text { perfusion for } \\
\text { decellularization }\end{array}$} & \multirow[t]{2}{*}{ Sample } & \multicolumn{4}{|c|}{ Histological details for HE staining (Fig.2B) } & \multirow{2}{*}{$\begin{array}{l}\text { Histological de } \\
\text { Arterialis }\end{array}$} \\
\hline & & Arterialis & Fibrosa & Spongiosa & Ventricularis & \\
\hline & $\begin{array}{l}\text { SAV } \\
(n=10)\end{array}$ & $\begin{array}{l}\text { Absence of } \\
\text { VECs }\end{array}$ & $\begin{array}{l}\text { Absence } \\
\text { of VECs } \\
\text { and } \\
\text { other } \\
\text { cells }\end{array}$ & $\begin{array}{l}\text { Lack of VICs and other } \\
\text { connective tissue cells }\end{array}$ & $\begin{array}{l}\text { Absence of VECs } \\
\text { and connective tissue cells }\end{array}$ & Elastin intact \\
\hline
\end{tabular}

Cross-linked conduit

Group C Sample Histological details for HE staining (Fig.2C)

Histological details for EVG staining (Fi

$0.2 \% \mathrm{GA}$

Arterialis

Fibrosa

Spongiosa Ventricularis

Arterialis

Fibr

SAV

$(n=10)$

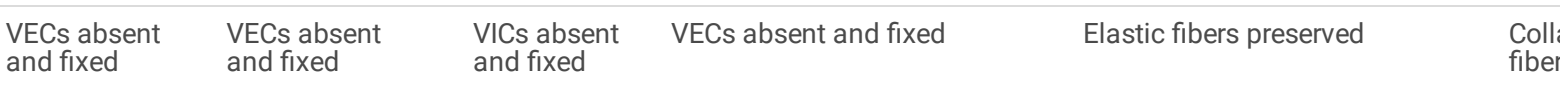

Table 3. Mechanical testing was done for Group A, Group B, and Group C and compared with Group A. Parameters analyzed are discussed in detail. 
Biomechanical Tensile Testing [Table:3]

\begin{tabular}{|c|c|c|c|}
\hline & $\begin{array}{l}\text { Group A } \\
(n=10)\end{array}$ & $\begin{array}{l}\text { Group B } \\
(n=10)\end{array}$ & $\begin{array}{l}\text { Group C } \\
(n=10)\end{array}$ \\
\hline Maximum load & $4.200 \mathrm{~N} \pm 0.1000$ & $3.073 \mathrm{~N} \pm 0.06429$ & $8.303 \mathrm{~N} \pm 0.4416$ \\
\hline$(\mathrm{N})$ & $(P<0.05)$ & $(P<0.05)$ & $(P<0.05)$ \\
\hline \multicolumn{4}{|l|}{ Maximum } \\
\hline \multirow{3}{*}{$\begin{array}{l}\text { Stress } \\
\left(\mathrm{N} / \mathrm{mm}^{2}\right)\end{array}$} & $0.03533 \mathrm{~N} / \mathrm{mm}^{2} \pm 0.002517$ & $0.002333 \mathrm{~N} / \mathrm{mm}^{2} \pm 0.001528$ & $0.02233 \mathrm{~N} / \mathrm{mm}^{2} \pm 0.001155$ \\
\hline & & & \\
\hline & $(P<0.05)$ & $(P<0.05)$ & $(P<0.05)$ \\
\hline \multicolumn{4}{|l|}{ Maximum } \\
\hline Displacement & $16.73 \mathrm{~mm} \pm 0.5508$ & $12.00 \mathrm{~mm} \pm 0.1000$ & $18.20 \mathrm{~mm} \pm 0.2646$ \\
\hline Till total tear & $(P<0.05)$ & $(P<0.05)$ & $(P<0.05)$ \\
\hline \multicolumn{4}{|l|}{$(\mathrm{mm})$} \\
\hline Maximum & $34.23 \% \pm 0.04933$ & $33.42 \% \pm 0.1582$ & $55.29 \% \pm 0.1677$ \\
\hline Strain & $(P<0.05)$ & $(P<0.05)$ & $(P<0.05)$ \\
\hline \multicolumn{4}{|l|}{ Till total tear } \\
\hline \multicolumn{4}{|l|}{ (\%) } \\
\hline Young's modulus & $3.067 \mathrm{MPa} \pm 0.05773$ & $0.1233 \mathrm{MPa} \pm 0.01528$ & $3.750 \mathrm{MPa} \pm 0.05291$ \\
\hline$(\mathrm{MPa})$ & $(P<0.05)$ & $(P<0.05)$ & $(P<0.05)$ \\
\hline \multicolumn{4}{|c|}{ LASE1 (Load at Specified Elongation) Stress (at 10\%) } \\
\hline \multirow[t]{2}{*}{$\left(\mathrm{N} / \mathrm{mm}^{2}\right)$} & $0.0260 \mathrm{~N} / \mathrm{mm}^{2} \pm 0.0010$ & $0.003333 \mathrm{~N} / \mathrm{mm}^{2} \pm 0.0005774$ & $0.001333 \mathrm{~N} / \mathrm{mm}^{2} \pm 0.0005774$ \\
\hline & $(P<0.05)$ & $(P<0.05)$ & $(P<0.05)$ \\
\hline \multicolumn{4}{|c|}{ LASE2 (Load at Specified Elongation) Stress (at 20\%) } \\
\hline \multirow[t]{2}{*}{$\left(\mathrm{N} / \mathrm{mm}^{2}\right)$} & $0.02067 \mathrm{~N} / \mathrm{mm}^{2} \pm 0.0005774$ & $0.0040 \mathrm{~N} / \mathrm{mm}^{2} \pm 0.0$ & $0.002967 \mathrm{~N} / \mathrm{mm}^{2} \pm 5.774 \mathrm{e}-005$ \\
\hline & $(\mathrm{P}<0.05)$ & $(\mathrm{P}<0.05)$ & $(P<0.05)$ \\
\hline
\end{tabular}

\section{Figures}




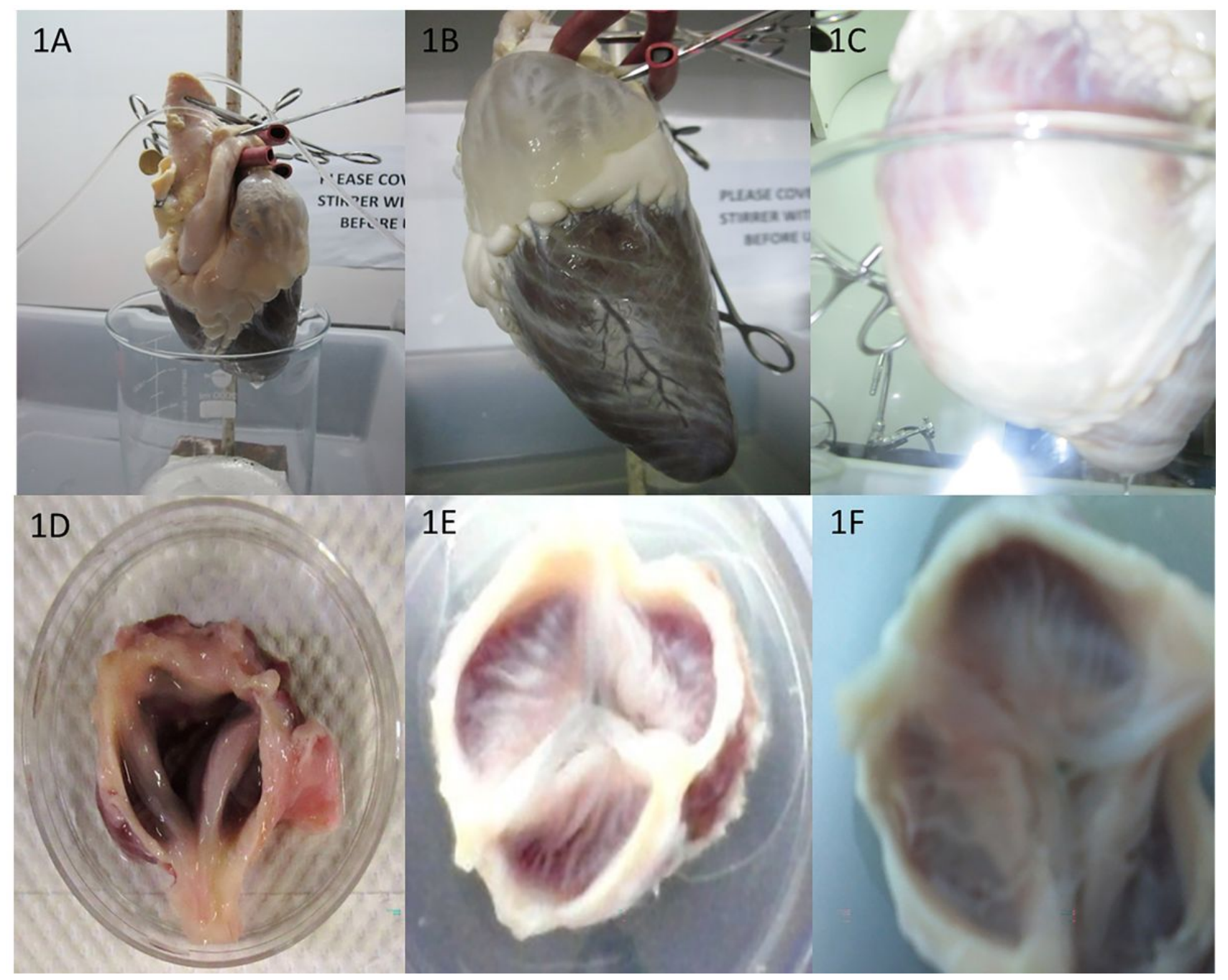

\section{Figure 1}

Sheep heart perfusion from the aorta, pulmonary artery, and coronary artery (Fig.1A). Progress of decellularization shows stripping away cells from the auricular zone and moving towards ventricular chambers and cardiac muscles (Fig.1B). Complete decellularized ghost sheep heart after 12 days resembling coronary arteries, fatty patches, circumflex vein, and other vasculature is seen (Fig.1C). Surgically dissected aortic valve from Group A (control) showing valvular leaflets (cups) and aortic orifice (Fig.1D). Surgically removed aortic valve after perfusion with ghost appearance (Fig.1E). Surgically-removed aortic valve after perfusion-based decellularization and cross-linking with $0.2 \%$ glutaraldehyde indicating robust nature (Fig. $1 \mathrm{~F})$. 

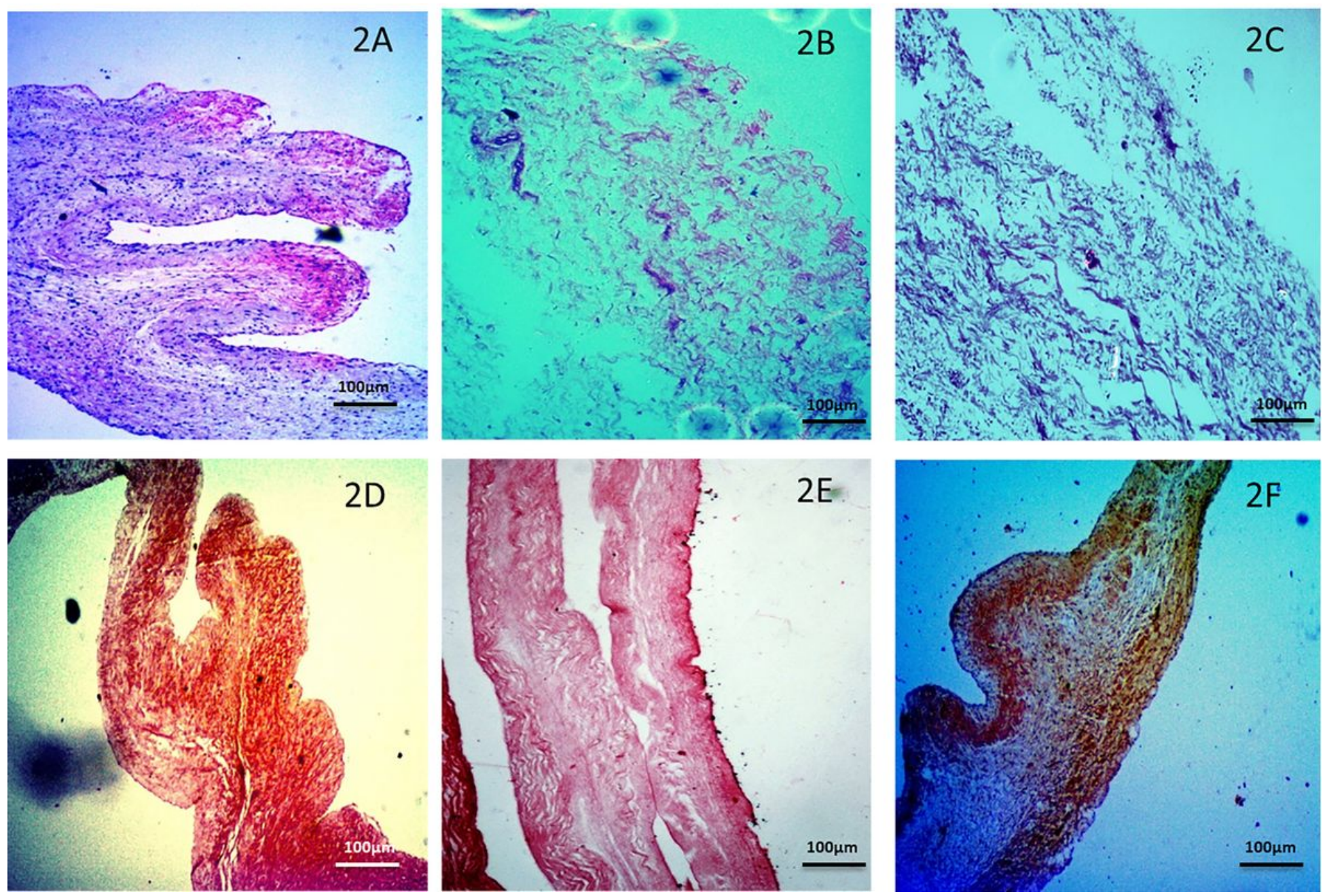

\section{Figure 2}

HE-staining for Group A shows cells in arterialis, fibrosa, spongiosa regions in the blue and pinkish counter background (2A). Group B (Fig.2B) and Group C (Fig.2C) show the complete absence of cells from valvular leaflets with the only blue-pinkish stained matrix. EVG staining for Group A shows the stained collagen and elastin in arterialis, fibrosa, spongiosa in deep red and yellowish appearance (Fig. 2D). Elastin and Collagen staining for Group B (Fig.2E) and Group C (Fig.2F) show preserved extracellular matrix with valvular textures (Table.2). 


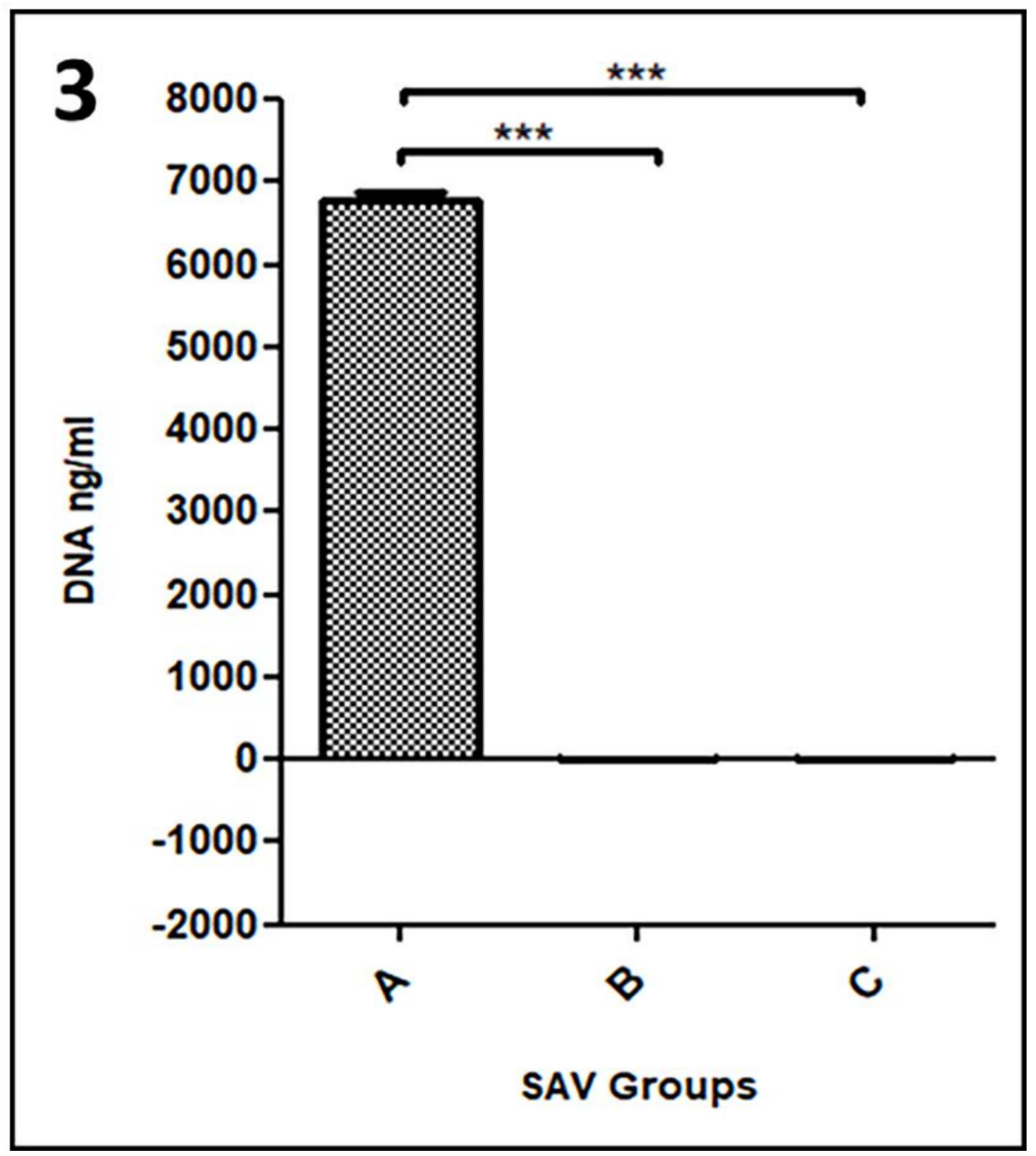

Figure 3

The DNA quantification showed the absence of genetic material from Group B and Group C valvular leaflets ( $n=10)$ and showed One way ANOVA *** $<<0.05$ level of significance (Dunnet Test). Group A showed the occurrence of DNA in valvular tissue, which was higher than decellularised samples (Dunnet Test). 


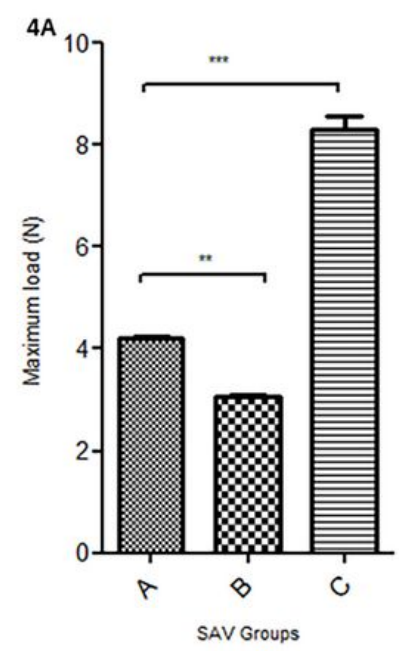

4E

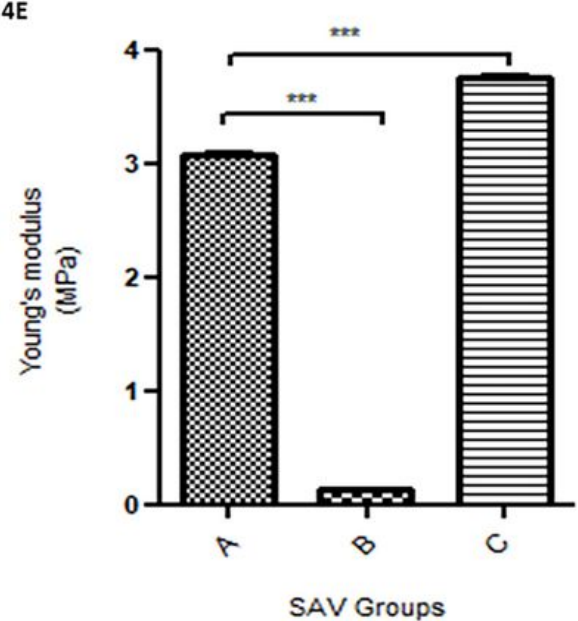

$4 B$

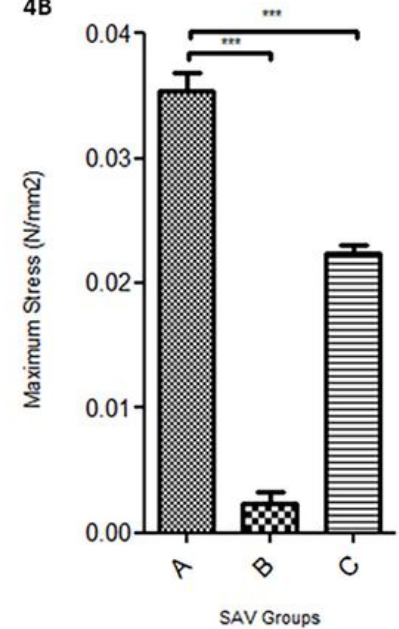

$4 C$

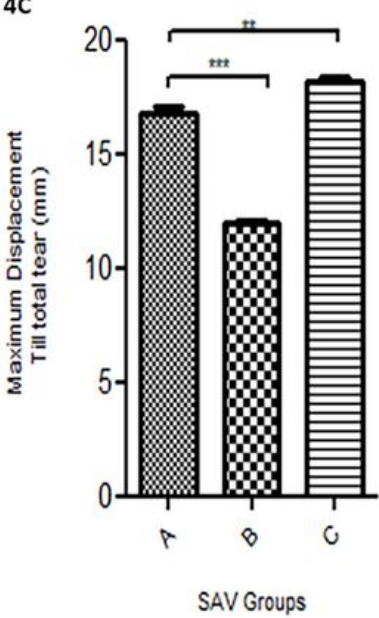

4D

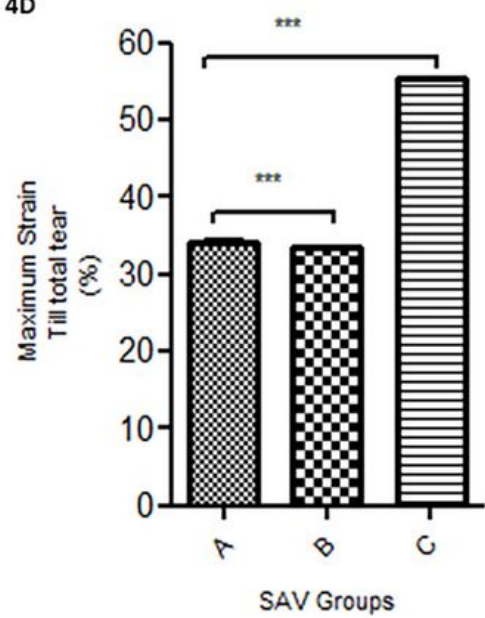

4F

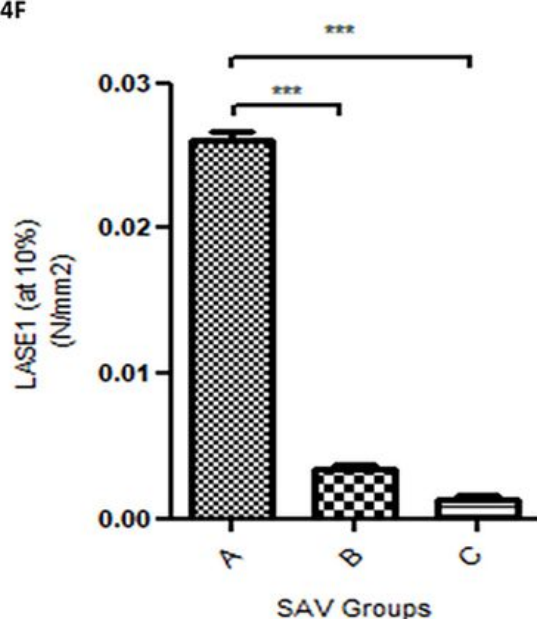

$4 G$

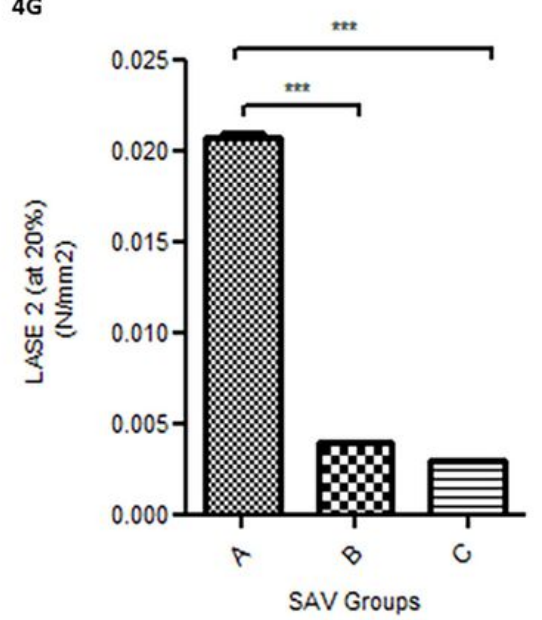

Figure 4

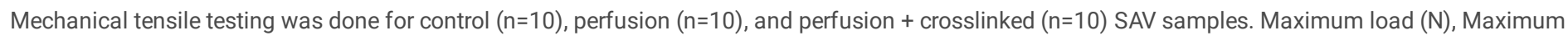

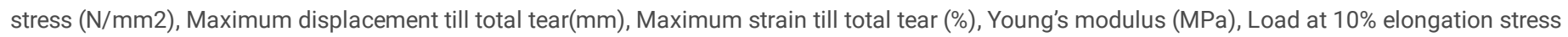

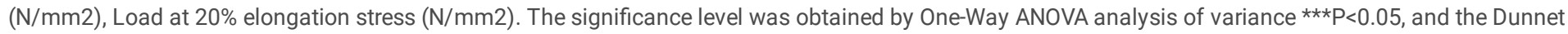
test was performed (Table.3). 

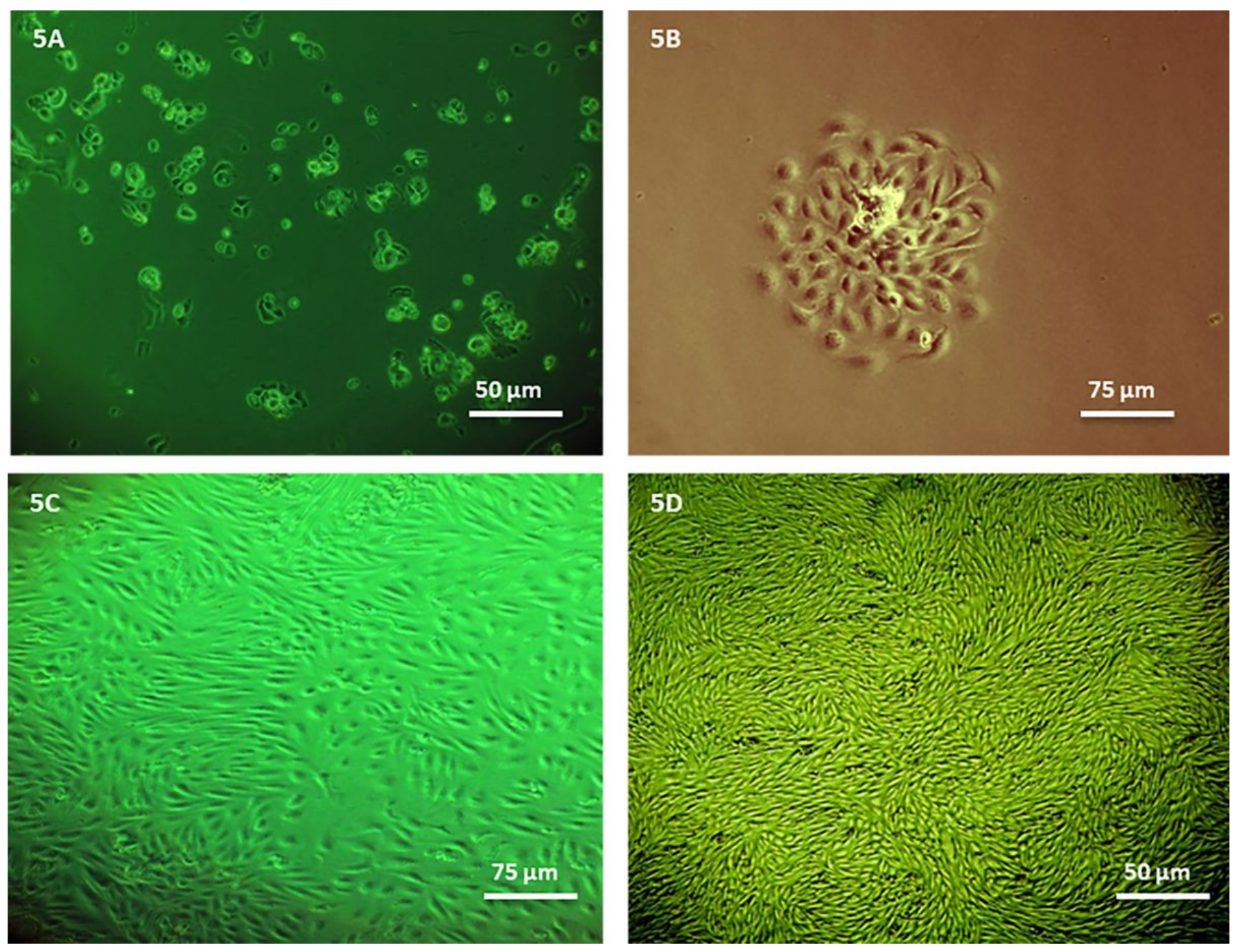

\section{Figure 5}

The image shows HUVECs in culture on day 0 (Fig.5A). HUVECs clonal formation in culture from single endothelial cells showing pebble shape phenotype (Fig.5B). HUVECs achieved almost confluence on day 10 (Fig.5C). HUVECs entirely occupied the culture surface on day 12 th showing an infinity pattern resembling cobblestone grassland (Fig.5D). 


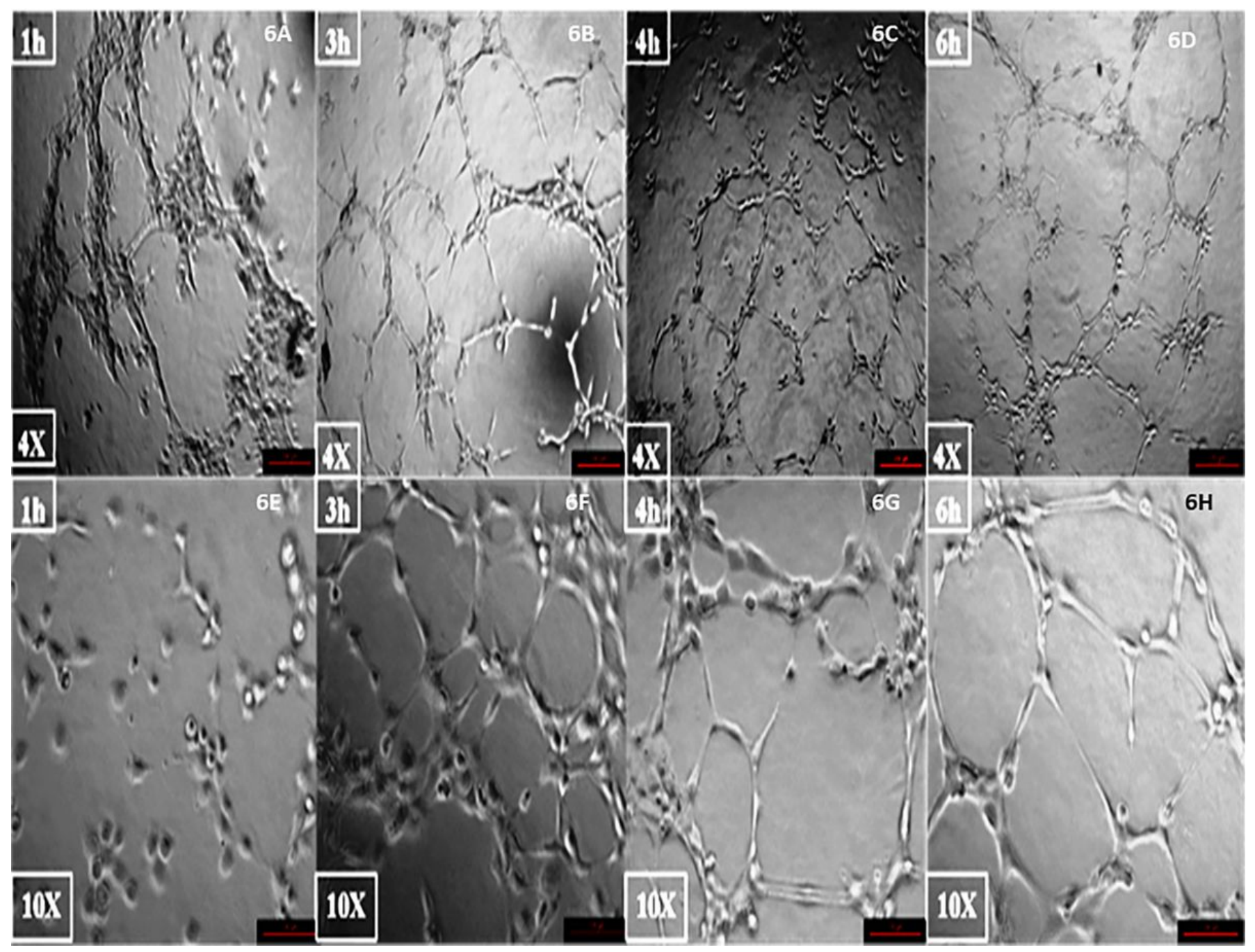

Figure 6

Matrigel assay showing angiogenesis at $1 \mathrm{~h}, 2 \mathrm{~h}, 3 \mathrm{~h}, 4 \mathrm{~h}$, and $6 \mathrm{~h}$ capillary tube-like morphology is seen for HUVECs remodeling. 


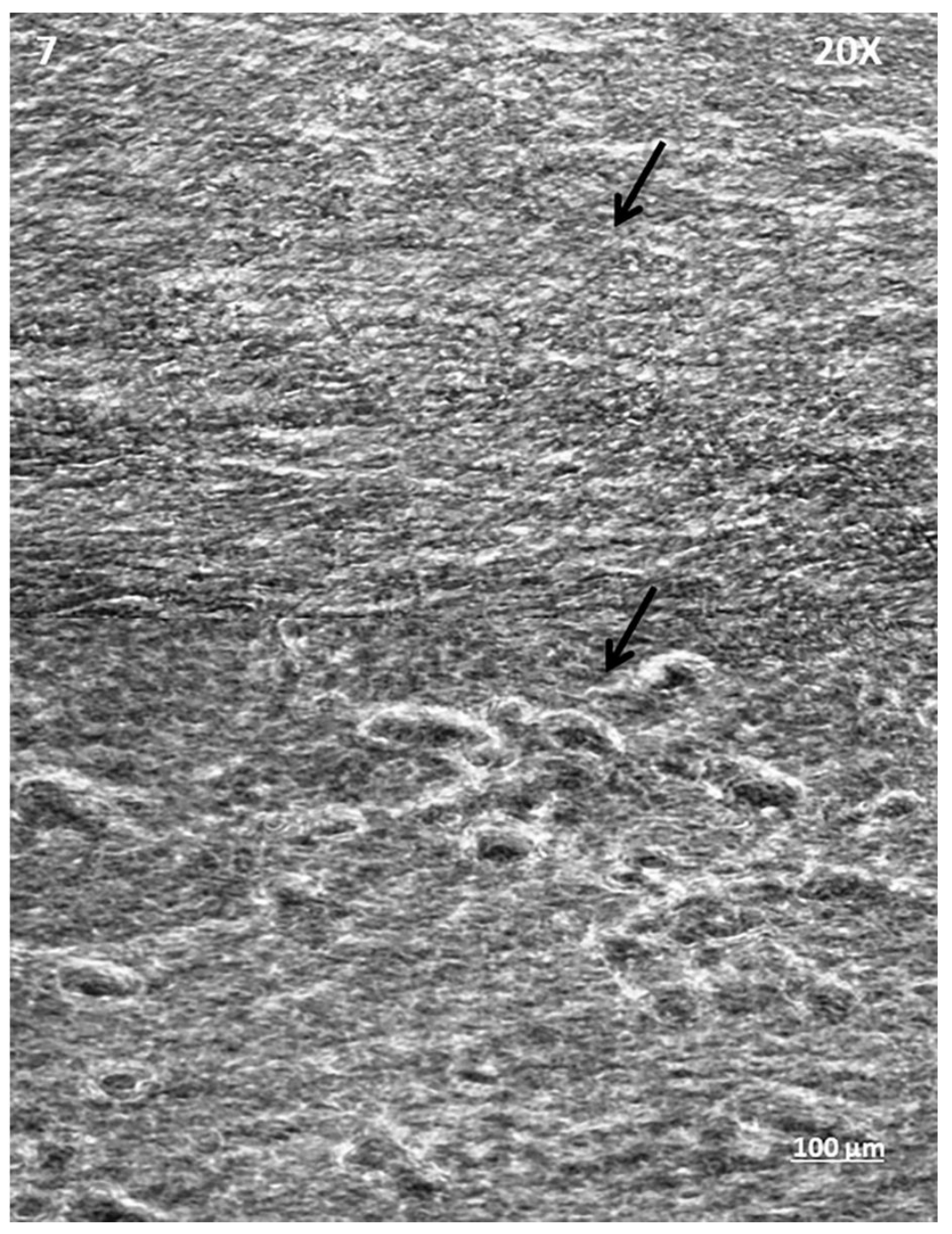

\section{Figure 7}

HUVECs are expanding on the valvular leaflet surface showing cell division and alignment as per the matrix texture (Fig.7). 

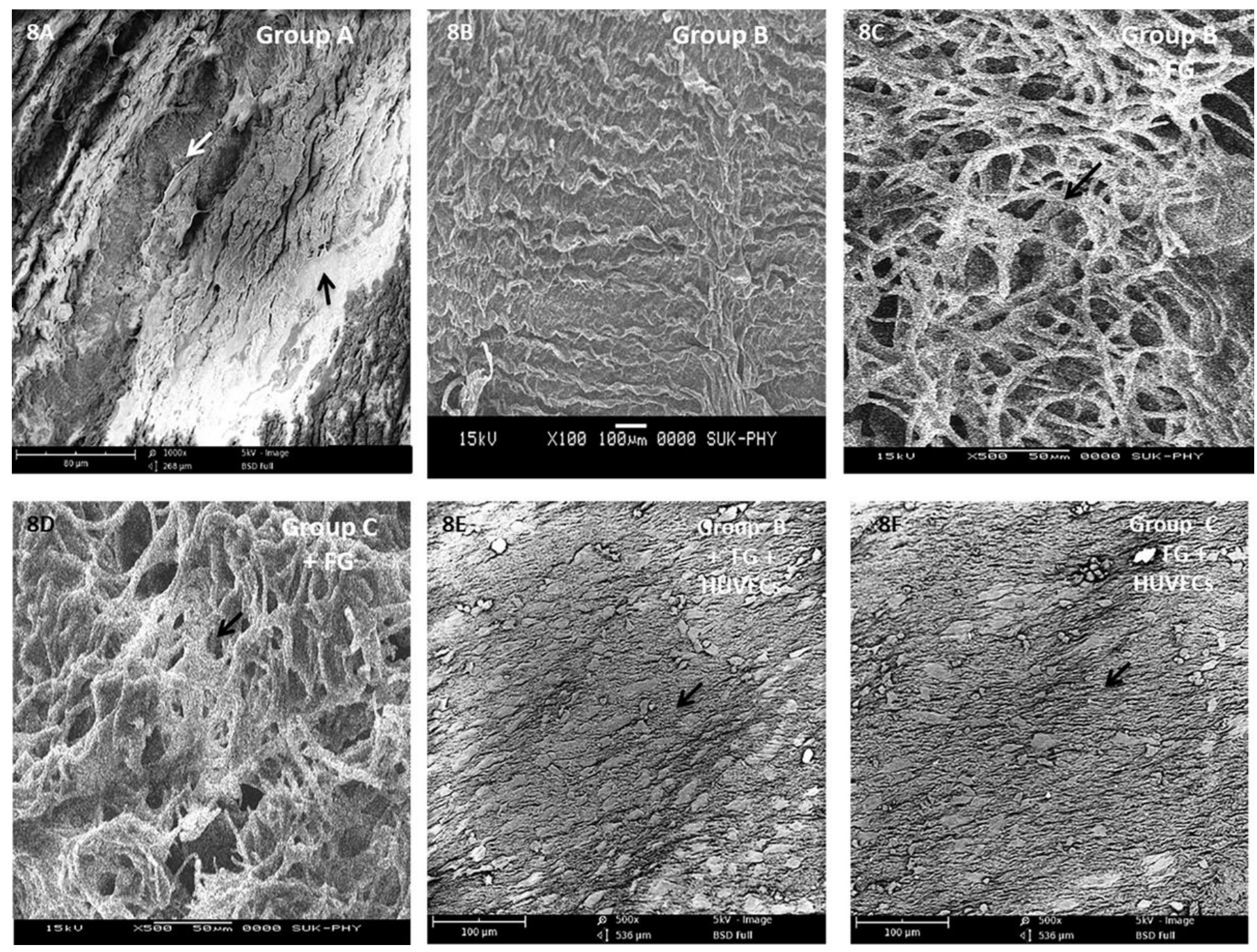

Figure 8

Group A shows the occurrence of valvular endothelial cells from the ventricularis region (Fig. 8A). The valvular leaflet surface is devoid of cells showing a valvular leaflet matrix (Fig.8B). The fibrin glue meshwork on the Group B (Fig.8C) and Group C (Fig.8D) surface show knitted, woven web morphology. The endothelial cells proliferation on Group B (Fig.8E) and Group C (Fig.8F) valvular leaflet surface showed parallel orientation and alignment as per the matrix surface.
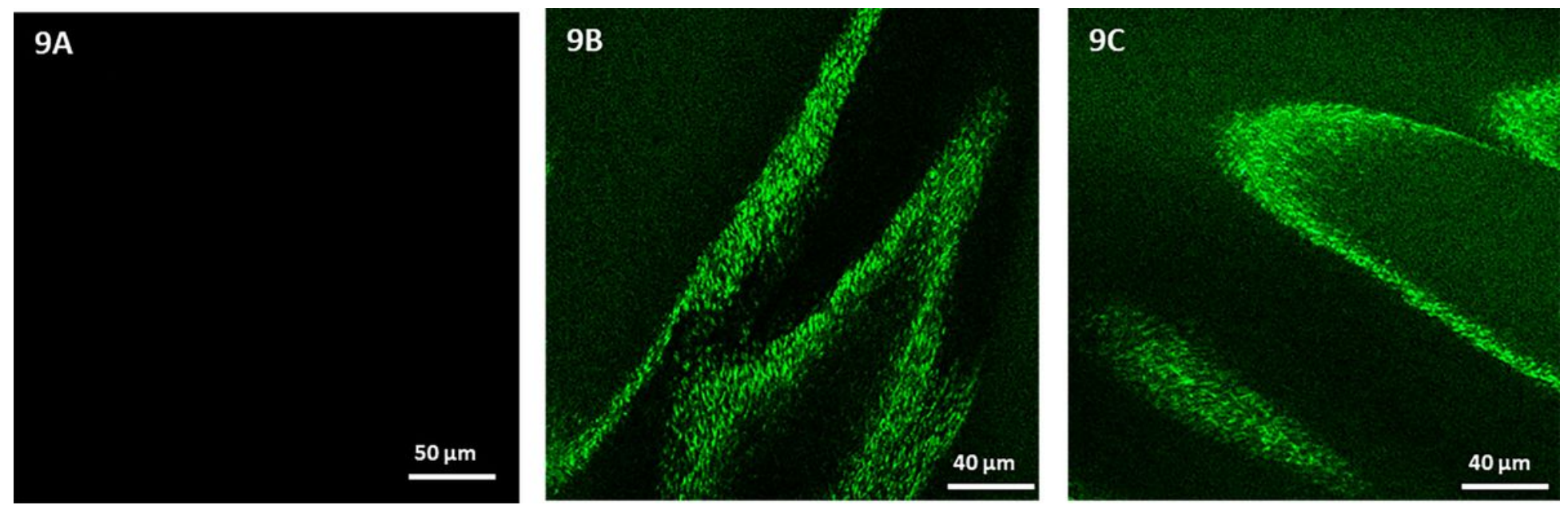

Figure 9

FDA/PI staining for Group B (Fig.9B) and Group C (Fig. 9C) showed cell viability on the SAV surfaces. Negative staining showed the absence of fluorescence (Fig.9A). 

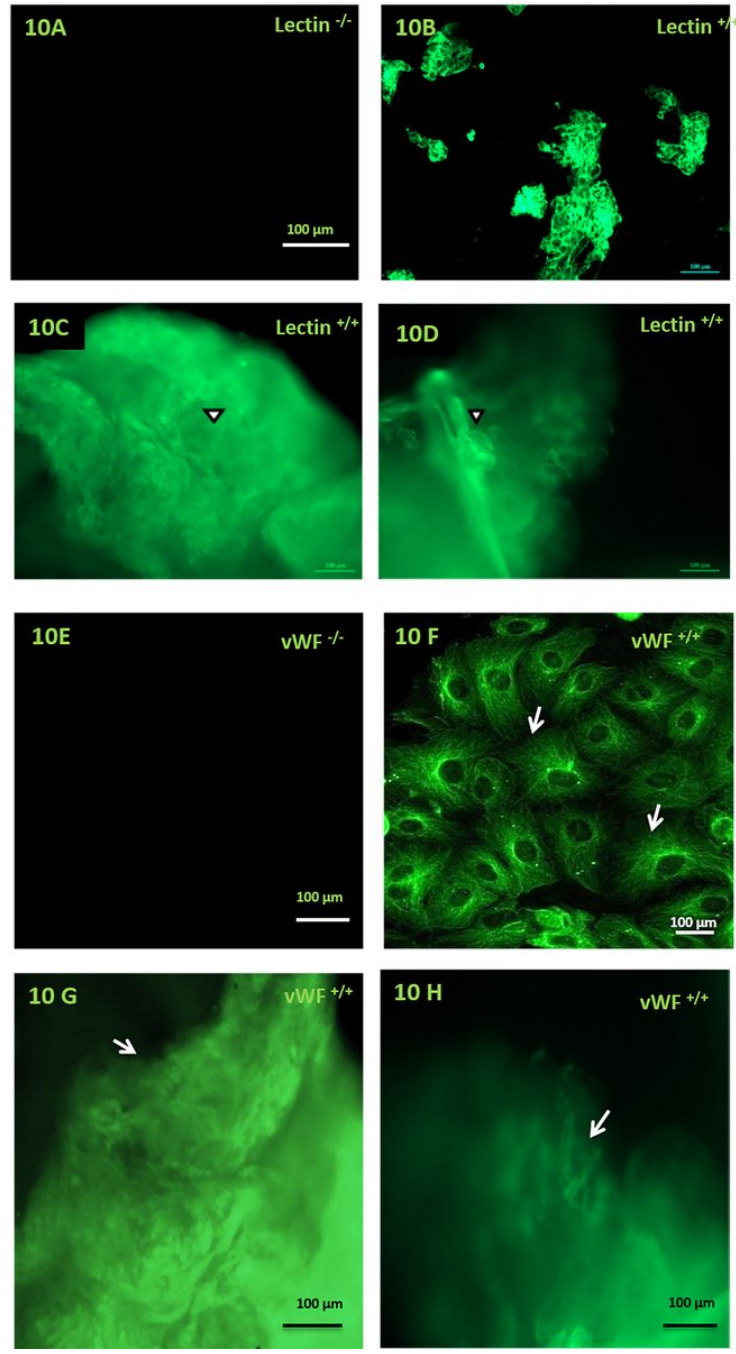

\section{Figure 10}

Lectin-/- expression was seen with no fluorescence signal (Fig.10A). The HUVECs cultured showed a lectin+/+ fluorescence signal in the cluster colonies (Fig.10B). Lectin+/+ positive signals were detected throughout the entire valvular leaflets of Group B (Fig.10C) and Group C (Fig.10.D), establishing the complete valvular surface re-endothelialization. vWF-/- signal was seen with the absence of any image (Fig.10E). vWF+/+ signal was seen in culture HIVECs (Fig.10F) in the cytosol area of the cells. vWF+/+ signal was also expressed on re-endothelialized SAV Group B (Fig.10G) and Group C (Fig.10H) scaffolds, making it a characterized leaflet bioprosthesis. 


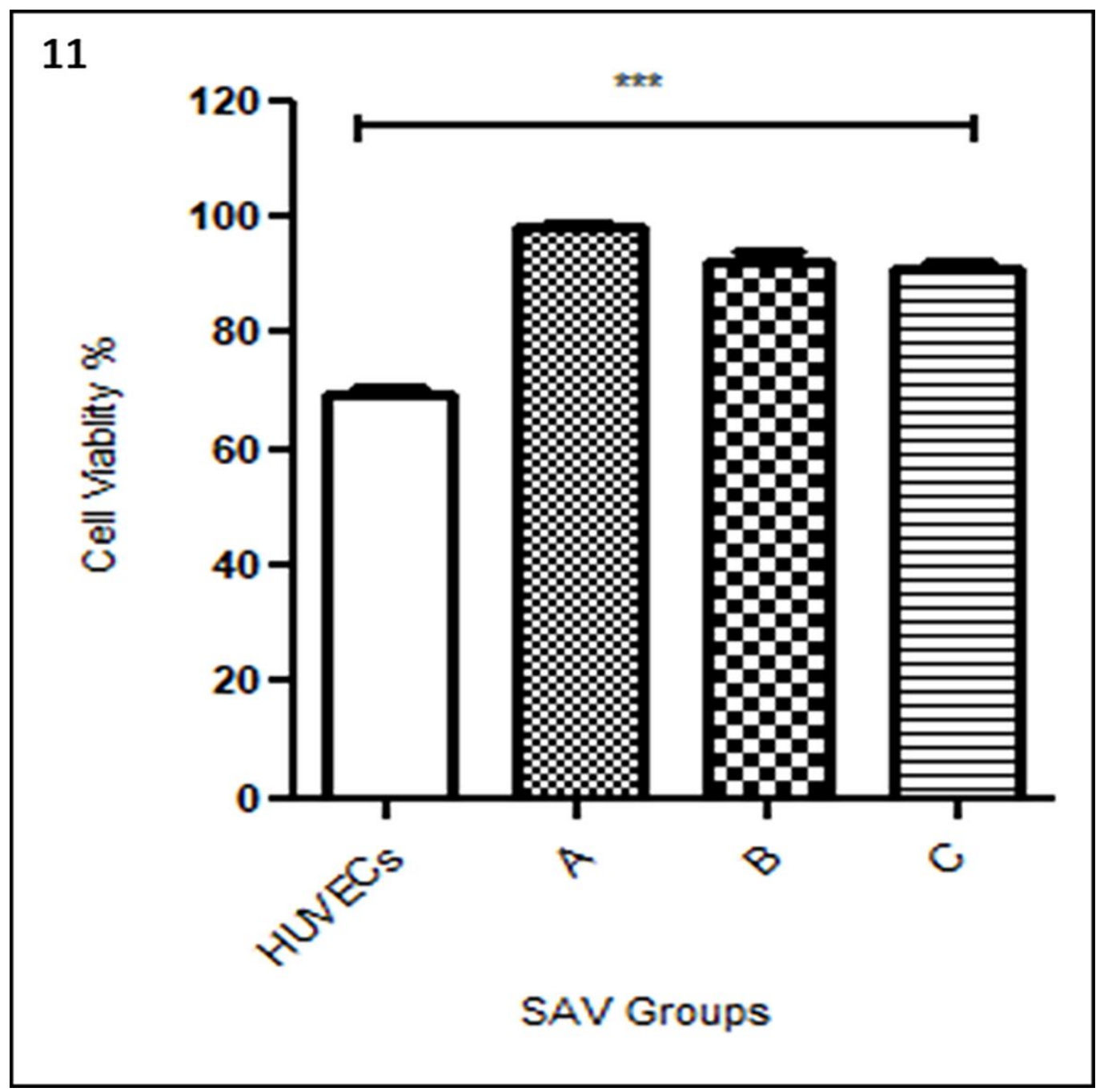

Figure 11

The metabolic activity of HUVECs on the valvular leaflet surface was calculated in formazan dye formation (MTT assay). The HUVECs in culture showed lesser cell viability or formazan formation in direct comparison to Group A ( $n=10)$, Group B $(n=10)$, and Group C ( $n=10)$ (Fig.11). Dunnet test was performed to compare the control group with other experimental sets. One-Way ANOVA showed the level of significance $* \star * P<0.05$ (Mean \pm S.D) (Dunnet Test). The level of significance was obtained for cells in culture and SAV groups (Dunnet test). 